\title{
A Novel Group Decision-Making Method Based on Generalized Distance Measures of PLTSs on E-Commerce Shopping
}

\author{
Juxiang Wang $\mathbb{D},{ }^{1,2}$ Jian Yuan, ${ }^{1}$ Jiajing Zhang, ${ }^{1}$ and Miao Tang $\mathbb{D}^{3}$ \\ ${ }^{1}$ School of Mathematics and Physics, Anhui Jianzhu University, Hefei 230601, China \\ ${ }^{2}$ School of Management, Hefei University of Technology, Hefei 230009, China \\ ${ }^{3}$ Department of Applied Mathematics, Anhui Agricultural University, Hefei, Anhui 230036, China \\ Correspondence should be addressed to Miao Tang; tangmiao2021@163.com
}

Received 25 February 2021; Revised 5 April 2021; Accepted 7 April 2021; Published 9 June 2021

Academic Editor: Zeshui Xu

Copyright (c) 2021 Juxiang Wang et al. This is an open access article distributed under the Creative Commons Attribution License, which permits unrestricted use, distribution, and reproduction in any medium, provided the original work is properly cited.

In multiattribute group decision-making (MAGDM), due to quantity, fuzziness, and complexity of evaluation linguistic information on commodities, traditional distance measures need to be extended to the integration of evaluation information under a multigranular probabilistic linguistic environment. A more reasonable method is proposed to deal with the missing value in the evaluation information. On the basis of the generalized distance measures and filling in the missing evaluation information, some novel distance measures between two multigranular probabilistic linguistic term sets (PLTSs) are presented in this paper. Based on these distance measures, three extended decision-making (DM) algorithms based on TOPSIS, the extended TOPSIS, and VIKOR are proposed, which are MGPL-TOPSIS, MGPL-ETOPSIS, and MGPL-VIKOR, respectively. The case analyses on purchasing a car are provided to illustrate the application of the extended multiattribute group decision-making (MAGDM) algorithms. Then, sensitivity analyses based on PT are proposed as well. In particular, the extended TOPSIS method is presented. These results demonstrate the novelty, feasibility, and rationality of the distance measures between two multigranular PLTSs proposed in this paper.

\section{Introduction}

With the popularity of the Internet, online shopping has become an important way of daily shopping. Shopping on an e-commerce platform, one alternative can be evaluated on different platforms, or one alternative may be described on the same platform by different granular fuzzy linguistic information; for example, we suppose that a consumer wants to buy a new energy car from USD 20,000 to USD 30,000. In this case, they can visit the auto home website to learn about comments of these cars from other consumers and make a reasonable decision to buy a car. Consumers who have purchased these cars can comment on them through many channels. They can score cars on the same platform, post word-of-mouth comments, post through the community, or evaluate through different media. The granularity of evaluation information is different in these evaluation channels. How can we more effectively make purchase decisions of products with different granularity evaluation?
In DM, due to the complexity of the real world, Zadeh proposed fuzzy set [1]. Furthermore, Zadeh proposed linguistic variables to represent uncertain and imprecise information intuitively, expressing human thoughts better [2]. In practice, the DMs are always hesitant among some evaluation values, and then, Torra proposed hesitant fuzzy set (HFS) first [3]. The hesitant fuzzy linguistic term set (HFLTS) was proposed to tackle the flexibility of the membership degree of HFS [4]. However, in some cases, the linguistic variables may be uncertain because of the complexity of DM problems, and the DMs may have different preferences with different belief degrees [5], possibility distributions [6], and importance degrees [7]. Then, using several linguistic terms to express evaluation information is more scientific. In this case, the hesitant fuzzy set based on probability was proposed as the probability-based hesitant fuzzy set (PHFS) [8, 9], and probabilistic linguistic term set (PLTS) by Qi Pang et al. is proposed to describe the object more effectively [10]. The PLTSs allow the DMs to give several linguistic terms, serving as the value of a linguistic 
variable, which enriches the flexibility of the expression of linguistic information. The DMs can express their linguistic evaluations or preference information better. Meanwhile, the PLTSs can provide different importance degrees or weights of all the possible evaluation preferences of one object.

The traditional method for group decision-making (GDM) under the same granular linguistic information cannot integrate hybrid evaluation information. Therefore, multigranular linguistic term sets need to be described efficiently. Then, how can two PLTSs with multigranular probabilistic linguistic information be measured? Considerable research has been conducted about the distance measures; for example, Zhai et al. presented probabilistic interval-valued intuitionistic hesitant fuzzy sets [11]. Wu et al. proposed a probabilistic linguistic MULTIMOORA method in multicriteria group decisionmaking (MCGDM) based on the probabilistic linguistic expectation function [12]. However, a few research types on distance measures of PLTSs with multigranular linguistic information remain. Then, distance measures for PLTSs with multigranular linguistic details need to be extended. Some DM models have been used to deal with probabilistic linguistic information. Gou and Xu proposed a new score function of linguistic terms and defined the operations of PLTSs [13]. Pang et al. proposed a probabilistic linguistic representation model based on TOPSIS [10]. Liu and Li presented the PROMTHEE II method [14]. Liao et al. gave the PL-LINMAP method for multiple criteria decision-making (MCDM) with PLTSs [15]. Li and Wang presented an extended QUALIFLEX plan for selecting green suppliers [16]. $\mathrm{Wu}$ and Liao proposed the ORESTE method with probabilistic linguistic information [17]. Liao et al. proposed the PL-ELECTRE III method with PLTSs [18]. Abdolhamid et al. extended the VIKOR method for GDM with extended hesitant fuzzy linguistic information [19]. Zhang et al. proposed a probabilistic linguistic method based on VIKOR to evaluate green supply chain initiatives [20]. Zhang and $\mathrm{Xu}$ et al. used the probabilistic linguistic VIKOR method to tackle water-human harmony evaluation [21]. Gou et al. improved the VIKOR method for the application of smart healthcare with probabilistic double hierarchy linguistic term set [22].

Some researchers have applied the PLTS to solve some practical problems; for example, Hao et al. presented a probabilistic dual-hesitant fuzzy set and its application in risk evaluation [23]. Gao et al. proposed a dynamic reference point method for emergency response [24]. Sharaf extended
TOPSIS to similarity measures for MADM and applied it to network selection [25]. Muhammad Sajjad Ali Khan et al. extended TOPSIS for MCDM [26]. Asif Ali and Tabasam Rashid presented a generalized interval-valued trapezoidal fuzzy best-worst MCDM method [27]. Rajkumar Verma presented MAGDM based on aggregation operators for linguistic trapezoidal fuzzy intuitionistic fuzzy sets [28].

However, the traditional linguistic information missing is usually filled with the minimum value or ignored. This method is flawed. Linguistic evaluation information is closely related with the psychological activities of decisionmakers. On the basis of the discussion above, we present a novel method to deal with the missing value in the evaluation information and generalized distance measures for the PLTSs with multigranular linguistic information. Then, we apply it to solve the problems of MAGDM on the decisionmaking of purchasing a car.

Based on the discussion above, this paper proposes distance measures for the PLTSs with multigranular linguistic information and then applies them in MAGDM.

\section{Preliminaries}

2.1. Linguistic Term Sets. The DMs can use LTSs to describe their preferences on the considered alternatives. The additive LTS is used most widely, which is defined as follows [28]:

$$
S=\left\{S_{\alpha} \mid \alpha=0,1, \ldots, g-1\right\},
$$

where $S$ is a $g$-granular fuzzy linguistic set; $S_{\alpha}$ is a linguistic variable with $S_{0}$ and $S_{g}$, namely, the lower and upper limits of the linguistic terms; and $g$ is a positive integer.

Considering the situations where the DMs may hesitate among several possible values in DM, which is similar to the hesitant fuzzy set, the concept of HFLTSs is as follows.

Definition 1 (see [29]). We let $S=\left\{S_{0}, S_{1}, \ldots S_{g-1}\right\}$ be a LTS, and then, HFLTs $b_{s}$ is an ordered finite subset of consecutive linguistic terms $S$.

\subsection{Probabilistic Linguistic Term Sets}

Definition 2 (see [10]). We let $S=\left\{S_{0}, S_{1}, \ldots S_{g-1}\right\}$ be an LTS. A PLTS is defined as

$$
L(P)=\left\{\left(L^{(k)} P^{(k)}\right) \mid L^{(k)} \in S, P^{(k)} \geq 0, k=1,2, \ldots, \# L(P), \sum_{k=1}^{\# L(P)} P^{(k)} \leq 1\right\}
$$

where $L^{(k)} P^{(k)}$ is the linguistic term $L^{(k)}$ associated with the probability $P^{(k)}$ and $\# L(P)$ is the number of all different linguistic terms in $L(P)$.

If $\sum_{k=1}^{\# L(P)} P(k)=1$, then we obtain the complete information on the probabilistic distribution with all the possible linguistic terms. If $\sum_{k=1}^{\# L(P)} P(k)<1$, then partial ignorance exists because of current insufficient evaluation information. Especially, $\quad \sum_{k=1}^{\# L(P)} P(k)=0$ means complete ignorance. Therefore, handling ignorance $L(P)$ is crucial research for the application of PLTSs. 
Definition 3 (see [10]). Given a PLTS $L(P)$ with $\sum_{k=1}^{\# L(P)}$ $P(k)<1$, then the associated PLTS $\dot{L}(P)$ is defined by

$$
\dot{L}(P)=\left\{L^{(k)}\left(\dot{P}^{(k)}\right) \mid k=1,2, \ldots, \# L(P)\right\},
$$

where $\dot{P}^{(k)}=P^{(k)} / \sum_{k=1}^{\# L(P)} P^{(k)}$ for all $k=1,2, \ldots, \# L(P)$.

\subsection{Multigranular Probabilistic Linguistic Term Sets}

$$
\begin{aligned}
& L_{1}(P)=\left\{L_{1}^{\left(k_{1}\right)}\left(P_{1}^{\left(k_{1}\right)}\right) \mid L_{1}^{\left(k_{1}\right)} \in S, P_{1}^{\left(k_{1}\right)} \geq 0, \quad k_{1}=1,2, \ldots, \# L_{1}\left(P_{1}\right), \sum_{k_{1}=1}^{\# L_{1}(P)} P_{1}^{\left(k_{1}\right)} \leq 1\right\}, \\
& L_{2}(P)=\left\{L_{2}^{\left(k_{2}\right)}\left(P_{2}^{\left(k_{2}\right)}\right) \mid L_{2}^{\left(k_{2}\right)} \in S^{\prime}, P_{2}^{\left(k_{2}\right)} \geq 0, \quad k_{2}=1,2, \ldots, \# L_{2}\left(P_{2}\right), \quad \sum_{k_{2}=1}^{\# L_{2}(P)} P_{2}^{\left(k_{2}\right)} \leq 1\right\},
\end{aligned}
$$

where $L_{1}^{\left(k_{1}\right)}\left(P_{1}^{\left(k_{1}\right)}\right)$ is the linguistic term $L_{1}^{\left(k_{1}\right)}$ associated with the probability $P_{1}^{\left(k_{1}\right)}$ and $L_{2}^{\left(k_{2}\right)}\left(P_{2}^{\left(k_{2}\right)}\right)$ is the linguistic term $L_{2}^{\left(k_{2}\right)}$ related to the probability $P_{2}^{\left(k_{2}\right)}$.

The numbers of linguistic terms in PLTSs are usually different for a DM. Therefore, the numbers of linguistic terms need to be added, in which numbers are relatively small. Then, the numbers of linguistic terms are the same.

The numbers of $L_{1}(P)$ and $L_{2}(P)$ are denoted as $\# L_{1}(P)$ and $\# L_{2}(P)$, respectively. If $\# L_{1}(P)<\# L_{2}(P)$, then $\# L_{1}(P)-$ $\# L_{2}(P)$ linguistic terms are added to $L_{2}(P)$, leading to the numbers of $L_{1}(P)$ and $L_{2}(P)$ to be equal. The added linguistic terms are the smallest ones, $L_{2}(P)$, and all the linguistic probabilities are zero.

Definition 5 (see [30]). We let $L_{1}(P)$ and $L_{2}(P)$ be two multigranular PLTSs. Then, the normalization processes are as follows:

(1) If $\sum_{k_{i}=1}^{\# L_{i}(P)} P_{i}^{\left(k_{i}\right)}<1$ by Definition 3, we calculate $\dot{L}_{i}(P), i=1,2$.

(2) If $\# L_{1}(P) \neq \# L_{2}(P)$, then by Definition 4 , we add some elements to the one with the smaller number of elements.

The PLTSs obtained by Definition 5 are denoted the normalized PLTSs. Conveniently, the normalized PLTSs are marked by $L_{1}(P)$ and $L_{2}(P)$ as well.
Definition 4 (see [30]). We let $S=\left\{S_{0}, S_{1}, \ldots S_{g-1}\right\}$ be $g$-granular LTS and $S^{\prime}=\left\{S_{0}, S_{1}, \ldots S_{g^{\prime-1}}\right\}$ be $g^{\prime}$-granular LTS. $L_{1}(P)$ and $L_{2}(P)$ are two different granular PLTSs on the attribute set $x=\left\{x_{1}, x_{2}, \ldots x_{n}\right\}$. Multigranular PLTSs can be defined as
Given the positions of elements in a PLTS are arbitrary, we need to obtain the ordered PLTSs first, leading to the operational results in PLTSs being determined directly.

Definition 6 (see [30]). We let $S=\left\{S_{0}, S_{1}, \ldots S_{g-1}\right\}$ be $g$ granular LTS. Given a PLTS, $L(P)=\left\{L^{(k)}\left(P^{(k)}\right) \mid L^{(k)} \in S\right.$, $\left.P^{(k)} \geq 0, k=1,2, \ldots \# L(P), \sum_{k=1}^{\# L(P)} P^{(k)} \leq 1\right\}$, and $r^{(k)}\left(L^{(k)}\right)$ is the subscript of the linguistic term $L^{(k)} L(P)$. It is named an ordered multigranular PLTS if the $L^{(k)}\left(P^{(k)}\right)(k=1,2$, $\ldots, \# L(P))$ descending order's values arrange $\alpha\left(L^{(k)}\right)$ $=\left(r^{(k)}\left(L^{(k)}\right) / g\right) \times P^{(k)}(k=1,2, \ldots, \# L(P))$ linguistic terms.

\section{Main Results in Discrete Case}

3.1. Generalized Distance Measures between Multigranular PLTSs. The traditional method of handling ignorance is not very scientific. Then, we extend the method and present the novel method to calculate the missing values. Inspired by [31], we present Definition 7 as follows.

Definition 7. We let $L_{1}(P)$ and $L_{2}(P)$ be two multigranular PLTSs. Then, the extended normalization processes are as follows:

(1) If $\sum_{k_{i}=1}^{\# L_{i}(P)} P_{i}^{\left(k_{i}\right)}<1$, then by Definition 3, we calculate $\dot{L}_{1}(P), i=1,2$.

(2) If $\# L_{1}(P) \neq \# L_{2}(P)$, then we add some elements to the one with

$$
\alpha\left(L^{(k)}\right)=t \times \max \left\{\frac{r^{(k)}\left(L^{(k)}\right)}{g}\right\}+(1-t) \min \left\{\frac{r^{(k)}\left(L^{(k)}\right)}{g}\right\}, 0 \leq t \leq 1, k=1,2, \ldots, \# L(P),
$$

where $t$ represents the risk preferences of the DMs. If $t>0.5$, it means the DMs are optimistic. If $t>0.5$, it means they are pessimistic. The value $t$ should be given by the DMs previously. 
Conveniently, we suppose that the PLTEs are the extended normalized and ordered multigranular PLTEs as Definitions 5 and 7 in all the following sections in this paper.

The normalized distance measures are extended, and the generalized distance measures between two multigranular PLTSs in discrete cases are presented as follows.

Example 1. Let $S=\left\{S_{0}, S_{1}, \ldots, S_{6}\right\}, L_{1}(P)=\left\{S_{3}(0.4), S_{2}\right.$ $\left.(0.2), S_{1}(0.2)\right\}$ and $L_{2}(P)=\left\{S_{3}(0.1), S_{2}(0.3)\right\}$ be two PLTSs, then (1) according to Definition $7, \dot{L}_{1}(P)=\left\{S_{3}(0.5), S_{2}\right.$ (0.25), $\left.S_{1}(0.25)\right\}, \quad \dot{L}_{2}(P)=\left\{S_{2}(0.75), S_{3}(0.25)\right\}$. (2) Since $\# L_{2}(P)<\# L_{1}(P)$, then we add the linguistic term $t \times(1.5 / 5)$ $+(1-t) \times(0.75 / 5)=0.15 t+0.15$. When $t=0.2$, then after normalization, $\alpha\left(\dot{L}_{1}^{(k)}\right)=\{0.3,0.1,0.05\}, \alpha\left(\dot{L}_{2}^{(k)}\right)=\{0.3,0.18$, $0.15\}$.

Conveniently, suppose the PLTEs are the extended normalized and ordered multigranular PLTEs as Definition 5 and Definition 7 in all the following sections in this paper.

The normalized distance measures are extended, and the generalized distance measures between two multigranular PLTSs in discrete cases are proposed as follows.

Definition 8. We let $L_{1}^{(k)}\left(P_{1}^{(k)}\right) \in L_{1}(P)$ and $L_{2}^{(k)}\left(P_{2}^{(k)}\right) \epsilon$ $L_{2}(P)$ be two PLTEs as in Definition 4 . Then, the distance measured between them is defined as

$$
d\left(L_{1}^{(k)}\left(P_{1}^{(k)}\right), L_{2}^{(k)}\left(P_{2}^{(k)}\right)\right)=\left|\alpha\left(L_{1}^{(k)}\left(P_{1}^{(k)}\right)\right)-\alpha\left(L_{2}^{(k)}\left(P_{2}^{(k)}\right)\right)\right|
$$

Example 2. Let $\alpha\left(\dot{L}_{1}^{(k)}\right)=\{0.1\}, \quad \alpha\left(\dot{L}_{2}^{(k)}\right)=\{0.18\}$, then $d\left(L_{1}^{(k)}\left(P_{1}^{(k)}\right), L_{2}^{(k)}\left(P_{2}^{(k)}\right)\right)=|0.1-0.18|=0.08$.

Definition 9. We let $L_{1}^{(k)}\left(P_{1}^{(k)}\right) \in L_{1}(P)$ and $L_{2}^{(k)}\left(P_{2}^{(k)}\right) \epsilon$ $L_{2}(P)$ be two PLTEs on the attribute set, denoted by $x=\left\{x_{1}, x_{2}, \ldots, x_{n}\right\}$, where $x_{j}$ is the $j$ th attribute of the alternatives and $j=1,2, \ldots, n$. Then, the generalized Hamming distance between $L_{1}(P)$ and $L_{2}(P)$ is defined as follows:

$$
d_{h d}\left(L_{1}(P), L_{2}(P)\right)=\frac{1}{L} \sum_{k=1}^{L} d\left(L_{1}^{(k)}\left(P_{1}^{(k)}\right) L_{2}^{(k)}\left(P_{2}^{(k)}\right)\right),
$$

where $\# L_{1}(P)=\# L_{2}(P)=L$.

Example 3. Let $\alpha\left(\dot{L}_{1}^{(k)}\right)=\{0.3,0.1,0.05\}$ and $\alpha\left(\dot{L}_{2}^{(k)}\right)=\{0.3$, $0.18,0.15\}$, then $d_{h d}\left(L_{1}(P), L_{2}(P)\right)=(1 / 3)(|0.3-0.3|+$ $|0.1-0.18|+|0.05-0.15|)=0.06$.

The generalized Euclidean distance between $L_{1}(P)$ and $L_{2}(P)$ is as follows:

$$
d_{e d}\left(L_{1}(P), L_{2}(P)\right)=\left[\frac{1}{L} \sum_{k=1}^{L}\left(d\left(L_{1}^{(k)}\left(P_{1}^{(k)}\right), L_{2}^{(k)}\left(P_{2}^{(k)}\right)\right)\right)^{2}\right]^{(1 / 2)} \text {. }
$$

Example 4. Let $\alpha\left(\dot{L}_{1}^{(k)}\right)=\{0.3,0.1,0.05\}$ and $\alpha\left(\dot{L}_{2}^{(k)}\right)=\{0.3$, $0.18,0.15\}$, then $d_{e d}\left(L_{1}(P), L_{2}(P)\right)=\sqrt{(1 / 3)\left[(0.3-0.3)^{2}\right.}$ $\left.+(0.1-0.18)^{2}+(0.05-0.15)^{2}\right]=0.0739$.
The generalized distance between $L_{1}(P)$ and $L_{2}(P)$ is as follows:

$$
d_{g d}\left(L_{1}(P), L_{2}(P)\right)=\left[\frac{1}{L} \sum_{k=1}^{L}\left(d\left(L_{1}^{(k)}\left(P_{1}^{(k)}\right), L_{2}^{(k)}\left(P_{2}^{(k)}\right)\right)\right)^{\lambda}\right]^{(1 / \lambda)}, \quad \lambda>0
$$

Significantly, if $g=g^{\prime}$, the generalized distance reduces to the generalized Hamming distance. If $n=1, \lambda=1$, the generalized distance reduces to the normalized Hamming distance. If $n=1, \lambda=2$, it reduces to the normalized Euclidean distance. Definition 9 extends the normalized Hamming distance and Euclidean distance.

3.2. Generalized Weighted Distance Measures between Multigranular PLTSs. We let $S=\left\{S_{0}, S_{1}, \ldots S_{g-1}\right\}$ be $g$-granular LTS and $S^{\prime}=\left\{S_{0}, S_{1}, \ldots S_{g^{\prime}-1}\right\}$ be $g^{\prime}$-granular LTS. $L_{1}(P)$ and $L_{2}(P)$ are two different granular PLTSs on the attribute set $x=\left\{x_{1}, x_{2}, \ldots, x_{n}\right\}$ with the weight vector $w=\left\{w_{1}, w_{2}, \ldots, w_{n}\right\}^{T}$, where $x_{j}$ is the $j$ th attribute of the alternatives, $j=1,2, \ldots, n, 0 \leq w_{j} \leq 1, \sum_{j=1}^{n} w_{j}=1$. Then, the normalized weighted distance measures are extended similar to Section 3.1. The generalized weighted distance measures between $L_{1}(P)$ and $L_{2}(P)$ are defined as follows.

Definition 10. A generalized weighted distance between $L_{1}(P)$ and $L_{2}(P)$ is defined as

$$
d_{\text {gwd }}\left(L_{1}(P), L_{2}(P)\right)=\left[\sum_{j=1}^{n} \frac{w_{j}}{L} \sum_{k=1}^{L}\left(d\left(L_{1}^{(k)}\left(P_{1}^{(k)}\right), L_{2}^{(k)}\left(P_{2}^{(k)}\right)\right)\right)^{\lambda}\right]^{1 / \lambda}, \quad \lambda>0 .
$$

Primarily, two exceptional cases of the generalized weighted distance are as follows:

(1) If $\lambda=1$, then generalized weighted distance reduces to the generalized weighted Hamming distance as follows:

$$
d_{\text {gwhd }}\left(L_{1}(P), L_{2}(P)\right)=\sum_{j=1}^{n} \frac{w_{j}}{L} \sum_{k=1}^{L}\left(d\left(L_{1}^{(k)}\left(P_{1}^{(k)}\right), L_{2}^{(k)}\left(P_{2}^{(k)}\right)\right)\right) .
$$

(2) If $\lambda=2$, then generalized weighted distance reduces to the generalized weighted Euclidean distance as follows:

$$
d_{\text {gwed }}\left(L_{1}(P), L_{2}(P)\right)=\left[\sum_{j=1}^{n} \frac{w_{j}}{L} \sum_{k=1}^{L}\left(d\left(L_{1}^{(k)}\left(P_{1}^{(k)}\right), L_{2}^{(k)}\left(P_{2}^{(k)}\right)\right)\right)^{2}\right]^{(1 / 2)} \text {. }
$$

\section{Applications of Generalized Distance Measures in MAGDM}

4.1. Description of the Problem. A set of alternatives $A=$ $\left(A_{1}, A_{2}, \ldots, A_{m}\right)$ is presented, the attribute vector is $x=\left(x_{1}, x_{2}, \ldots, x_{n}\right)^{T}, w=\left(w_{1}, w_{2}, \ldots, w_{n}\right)^{T}$ is the weight vector, and $x_{j}$ is the $j$ th attribute of the alternatives, 
$j=1,2 \ldots, n, 0 \leq w_{j} \leq 1, \sum_{j=1}^{n} w_{j}=1$. The DMs assess $m$ alternatives on $n$ attributes by utilizing a linguistic term set to get a set of linguistic decision matrices.

Then, the evaluation of linguistic information is used to make up a multigranular probabilistic linguistic decision matrix as follows:

$$
R=\left[L_{i j}(P)\right]_{m \times n}=\left[\begin{array}{cccc}
L_{11}(P) & L_{12}(P) & \cdots & L_{1 n}(P) \\
L_{21}(P) & L_{22}(P) & \cdots & L_{2 n}(P) \\
\vdots & \vdots & \ddots & \vdots \\
L_{m 1}(P) & L_{m 2}(P) & \cdots & L_{m n}(P)
\end{array}\right],
$$

where $L_{i j}(P)=\left\{L_{i j}^{k_{i j}}\left(P_{i j}^{k_{i j}}\right) \mid L_{i j}^{\left(k_{i j}\right)} \in S_{i}, P_{i j}^{k_{i j}} \leq 0, k_{i j}=1,2, \cdots\right.$, $\left.\# L_{i j}(P), \sum_{k_{i j}=1}^{\# L_{i j}(P)} P_{i j}^{\left(k_{i j}\right)} \leq 1\right\}$ is a multigranular PLTS denoting the degree of the alternative $A_{i}$ on the attribute $x_{j}, S_{i}=$ $\left\{S_{0}, S_{1}, \ldots, S_{g_{i}-1}\right\}$ is a $g_{i}$-granular fuzzy linguistic set, and $r_{i j}^{\left(k_{i j}\right)}$ is the subscript of the linguistic term $L_{i j}^{\left(k_{i j}\right)}\left(P_{i j}^{\left(k_{i j}\right)}\right)$, which is associated with the probability $P_{i j}^{\left(k_{i j}\right)}$, $i=1,2, \ldots, m, j=1,2, \ldots, n$.
In MAGDM problems, the attributes can be classified into two types: benefits and costs. The higher the benefit attribute, the better the situation, whereas the opposite it applies to the cost attribute. In this paper, we suppose that the attributes are benefits.

On the basis of the generalized distance measures of Section 3, the extended TOPSIS is presented as follows.

4.2. MGPL-TOPSIS Algorithm. MGPL-TOPSIS algorithm is a MAGDM approach based on TOPSIS under multigranular probabilistic fuzzy linguistic environment proposed as follows.

Step 1. Individual preferences over the alternatives on different attributes provided by experts are gathered as $R=\left[L_{i j}(P)\right]_{m \times n}$.

Step 2. (see [30]). The weight vector $w=\left(w_{1}, w_{2}, \ldots, w_{n}\right)^{T}$ of $n$ attributes $x=\left(x_{1}, x_{2}, \ldots, x_{n}\right)^{T}$ is computed as follows:

$$
\begin{aligned}
& E_{j}=\frac{1}{m} \sum_{i=1}^{m}\left(1-\frac{2}{L_{j} T} \sum_{i=1}^{L_{j}}\left(\left(1+q r_{i j}^{\left(k_{i j}\right)}\right)\right.\right. \\
& \left.\cdot \ln \left(1+q r_{i j}^{\left(k_{i j}\right)}\right)+\left(1+q\left(1-r_{\left(L_{j}-i+1\right) j}^{\left(k_{i j}\right)}\right)\right)\right) \\
& \cdot \ln \left(1+q\left(1-r\left(\begin{array}{l}
\left(k_{i j}\right) \\
\left(L_{j}-i+1\right) j
\end{array}\right)\right)\right) / 2 \\
& -\left(\left(2+q r_{i j}^{\left(k_{i j}\right)}+q\left(1-r \underset{\left(L_{j}-i+1\right) j}{\left(k_{i j}\right)}\right)\right) / 2\right)
\end{aligned}
$$

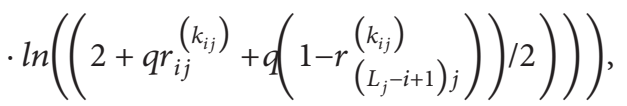

$$
\begin{aligned}
& w_{j}=\frac{1-E_{j}}{n-\sum_{j=1}^{n} E_{j}}, \quad i=1,2, \ldots, m, j=1,2, \ldots, n, L_{j}=\# L_{i j}(P),
\end{aligned}
$$

where $T=(1+q) \operatorname{In}(1+q)-(2+q)(\operatorname{In}(2+q)-\operatorname{In} 2), q>0$, $0 \leq w_{j} \leq 1$, and $\sum_{j=1}^{n} w_{j}=1$. In this paper, we let $q=2$ [30].

Step 3. The positive ideal solution and the negative ideal solution, respectively, are calculated.

The probabilistic linguistic positive ideal solution (PLPIS) and the probabilistic linguistic negative ideal solution (PLNIS) are defined, respectively.

The PLNIS of the alternatives is

$$
L^{+}=\left(L_{1}(P)^{+}, L_{2}(P)^{+}, \ldots, L_{n}(P)^{+}\right) .
$$

The PLNIS of the alternatives is

$$
L^{-}=\left(L_{1}(P)^{-}, L_{2}(P)^{-}, \ldots, L_{n}(P)^{-}\right),
$$

where $L_{j}(P)^{+}=L_{\Delta}$, in which $\Delta=\max _{i, j, k}\left\{\alpha\left(L_{i j}^{\left(k_{i j}\right)}\right)\right\}$, and $L_{j}(P)^{-}=L_{\nabla}$, in which $\nabla=\min _{i, j, k}\left\{\alpha\left(L_{i j}^{\left(k_{i j}\right)}\right)\right\}$.

$$
\alpha\left(L_{i j}^{\left(k_{i j}\right)}\right)=\frac{r_{i j}^{\left(k_{i j}\right)}\left(L_{i j}^{\left(k_{i j}\right)}\right)}{g_{i}} \times P_{i j}^{\left(k_{i j}\right)}, \quad i=1,2, \ldots, m, j=1,2, \ldots, n, k_{i j}=1,2, \ldots, \# L_{i j}(P) .
$$


Step 4. The distance between $A_{i}$ and $L^{+}$, denoted by $d\left(A_{i}, L^{+}\right)$, and the distance between $A_{i}$ and $L^{-}$, denoted by $d\left(A_{i}, L^{-}\right)$, are computed.

Step 5. The closeness degree of each alternative is computed as follows:

$$
\mathrm{CD}_{i}=\frac{(1-\delta) d\left(A_{i}, L^{-}\right)}{\delta d\left(A_{i}, L^{+}\right)+(1-\delta) d\left(A_{i}, L^{-}\right)}
$$

where the parameter $\delta \in[0,1]$ represents the risk preferences of the decision-makers. If $\delta<0.5$, then the DMs are optimistic. If $\delta>0.5$, then they are pessimistic. The value $\delta$ should be given by the DMs previously.

Step 6. The alternatives are ranked according to the values $\mathrm{CD}_{i}$ of $A_{i}$.

The larger the closeness degree, the better the alternative.

4.3. MGPL-ETOPSIS Algorithm. MGPL-ETOPSIS algorithm is based on the extended TOPSIS by Qi Pang et al. [10], which is a MAGDM approach under multigranular probabilistic fuzzy linguistic environment proposed as follows:

Step 1: individual preferences over the alternatives on different attributes provided by experts are gathered as $R=\left[L_{i j}(P)\right]_{m \times n}$.

Step 2: the weight vector (see [30]) $w=\left(w_{1}, w_{2}, \ldots\right.$, $\left.w_{n}\right)^{T}$ of $n$ attributes $x=\left(x_{1}, x_{2}, \ldots, x_{n}\right)^{T}$ is computed as follows, as seen in equation (14).

Step 3: the positive ideal solution and the negative ideal solution, respectively, are calculated.

Step 4: the distance between $A_{i}$ and $L^{+}$, denoted by $d\left(A_{i}, L^{+}\right)$, and the distance between $A_{i}$ and $L^{-}$, denoted by $d\left(A_{i}, L^{-}\right)$, are computed.

Step 5: compute the closeness coefficient $\mathrm{CI}_{i}$ of each alternative $A_{i}$ as follows:

$$
\mathrm{CI}_{i}=\frac{d\left(A_{i}, L^{-}\right)}{d_{\max }\left(A_{i}, L^{-}\right)}-\frac{d\left(A_{i}, L^{+}\right)}{d_{\min }\left(A_{i}, L^{+}\right)} .
$$

Rank the alternatives by $\mathrm{CI}_{i}$. Obviously, the bigger the closeness coefficient, the better the alternative.

4.4. MGPL-VIKOR Algorithm. MGPL-VIKOR algorithm is a MAGDM approach based on VIKOR under multigranular probabilistic fuzzy linguistic environment proposed as follows:

Step 1: individual preferences over the alternatives on different attributes provided by experts are gathered as $R=\left[L_{i j}(P)\right]_{m \times n}$.

Step 2: the weight vector (see [30]) $w=\left(w_{1}, w_{2}, \ldots\right.$, $\left.w_{n}\right)^{T}$ of $n$ attributes $x=\left(x_{1}, x_{2}, \ldots, x_{n}\right)^{T}$ is computed as follows, as seen in equation (14).

Step 3: compute the distance $d\left(L_{i j}(P), L_{j}(P)^{+}\right)$and $d\left(L_{j}(P)^{+}, L_{j}(P)^{-}\right)$.
Step 4: compute the whole benefit $\mathrm{MU}_{i}$ and individual regret $\mathrm{MR}_{i}, \mathrm{MU}^{+}, \mathrm{MU}^{-}, \mathrm{MR}^{+}$, and $\mathrm{MR}^{-}$, respectively, $i=1,2, \ldots, m, j=1,2, \ldots, n$.

Step 5: compute the compromise index $\mathrm{MC}_{i}$ of $A_{i}$. Rank the alternatives, according to $\mathrm{MC}_{i}$. Obviously, the bigger the compromise index, the better the alternative [31].

The definitions of whole benefit, $\mathrm{MU}_{i}$, individual regret $\mathrm{MR}_{i}$, and the compromise index $\mathrm{MC}_{i}$, are as follows:

$$
\begin{aligned}
\mathrm{MU}_{i} & =\sum_{j=1}^{n} w_{j} \frac{d\left(L_{i j}(P), L_{j}(P)^{+}\right)}{d\left(L_{j}(P)^{+}, L_{j}(P)^{-}\right)}, \\
\mathrm{MR}_{i} & =\max \left[w_{j} \frac{d\left(L_{i j}(P), L_{j}(P)^{+}\right)}{d\left(L_{j}(P)^{+}, L_{j}(P)^{-}\right)}\right] \\
\mathrm{MC}_{i} & =v \frac{\mathrm{MU}_{i}-\mathrm{MU}^{+}}{\mathrm{MU}^{-}-\mathrm{MU}^{+}}+(1-v) \frac{\mathrm{MR}_{i}-\mathrm{MR}^{+}}{\mathrm{MR}^{-}-\mathrm{MR}^{+}}
\end{aligned}
$$

where $\mathrm{MU}^{+}=\max \left\{\mathrm{MU}_{i}\right\}, \mathrm{MU}^{-}=\min \left\{\mathrm{MU}_{i}\right\}, \mathrm{MR}^{+}=\max$ $\left\{\mathrm{MR}_{i}\right\}$, and $\mathrm{MR}^{-}=\min \left\{\mathrm{MR}_{i}\right\}, i=1,2, \ldots, m$. The parameter $v$ denotes the weight of the strategy of the maximum whole benefits, whereas $1-v$ is the weight of the individual regret strategy.

Rank the alternatives by $\mathrm{MC}_{i}$. The higher the $\mathrm{MC}_{i}$, the more preferred the alternative.

\section{Illustrative Example}

In the real world, people usually encounter the DM problems, such as healthcare management, project evaluation, education assessment, emergency management, and smart city construction, especially COVID-19 prevention and control; for example, someone will purchase one of the five new energy cars, who can find all kinds of evaluation information of these five cars through the network for the development of Internet information. The more professional and popular website about auto information is the "Auto Home" website. Some evaluation information of these cars is presented on the "Auto Home" website in three ways: scoring data, word-of-mouth data, and forum reviews on eight attributes. The eight attributes are space $\left(x_{1}\right)$, power $\left(x_{2}\right)$, manipulate $\left(x_{3}\right)$, power consumption $\left(x_{4}\right)$, comfort $\left(x_{5}\right)$, appearance $\left(x_{6}\right)$, interior decoration $\left(x_{7}\right)$, and cost performance $\left(x_{8}\right)$, respectively. The five cars are Tiggo3Xe $\left(A_{1}\right)$, ZhongTaiE200 $\left(A_{2}\right)$, Yuan New Energy $\left(A_{3}\right)$, Song New Energy $\left(A_{4}\right)$, and Qin Pro New Energy $\left(A_{5}\right)$. Given that scoring data online is a five-point system, and the scoring data can be mapped to 5-granular linguistic term sets. The average word-of-mouth data can be mapped to 7-granular linguistic term sets. Because of the complexity of forum reviews, this information can be mapped to 9-granular linguistic term sets.

Then, we use the generalized distance measure formula (equation (10)) as an example to apply the algorithm (Section 4.2) as follows. 
5.1. Application of MGPL-TOPSIS Algorithm. The application of the algorithm based on MGPL-TOPSIS is shown as follows (Tables 1-13):

Step 1: the users' evaluation information on the "Auto Home" website until Feb 17 in 2019 is collected (Tables 1-3).

Here, the scoring data are the five cars' final average values on eight attributes from the scoring data (Table 1). The evaluation information is the general impression of the word-of-mouth data (Table 2). The evaluation information is from the forum review data (Table 3). These data are obtained on the "Auto Home" website.

Then, we obtain the users' overall evaluation linguistic term sets (Table 4).

Then, we obtain the users' overall evaluation probabilistic linguistic term sets by Definition 7 . We suppose that the DMs are the most pessimistic $t=0$. The probability of evaluation information is calculated by probability definition, and we obtain the probabilistic linguistic evaluation matrix as follows (Table 5).

Then, we obtain the extended normalized DM matrix by Definition 7 (Table 6).

Step 2: the weight vector is calculated on the eight attributes by equation (14) (Table 7).

Step 3: the PLPIS and PLNIS are calculated, respectively (Tables 8 and 9). To calculate conveniently, we only denote $\alpha_{i}$ instead of $S_{\alpha_{i}}$ :

Step 4: $d\left(A_{i}, L^{-}\right)$and $d\left(A_{i}, L^{+}\right), i=1,2, \ldots, 5$ are calculated. The results are as follows (Tables 10 and 11).

Step 5: the closeness coefficient $\mathrm{CD}_{i}$ of $A_{i}(i=1,2, \ldots, 5)$ by equation (18) is calculated. The results are as follows (Table 12).

Step 6: The alternatives are ranked by $\mathrm{CD}_{i}$. Here, we let $\delta=0.5$ (Table 13 and Figure 1).

Table 13 and Figure 1 show that when $\lambda=1$, the ranking of $A_{i}(i=1,2, \ldots, 5)$ is " $A_{1}>A_{5}>A_{4}>A_{2}>A_{3}$," when $\lambda=2$, the ranking is " $A_{1}>A_{5}>A_{4}>A_{3}>A_{2}$," and when $\lambda=3,4, \ldots, 10$, the ranking is " $A_{5}>A_{1}>A_{4}>A_{3}>A_{2}$," illustrating that the ranking results are changed with $\lambda$. When $\lambda$ is different, the ranking result is different. When $\lambda=3$, the ranking is stable, demonstrating that the algorithm based on TOPSIS is available.

In real life, we can use the MGPL-TOPSIS algorithm to deal with some GDM problems, such as environmental pollution management, urban traffic planning, treatment options, project evaluation, education assessment, emergency management, and smart city construction, especially COVID-19 prevention and control. The calculation method of the MGPL-TOPSIS algorithm is more convenient and effective, and the scientific method to make up for the DMs' missing information reduces the loss of effective information, so as to make the DM results more objective and effective.

5.2. Comparative Analysis and Discussion. To demonstrate the feasibility and efficiency of the algorithm based on generalized distance measures of the PLTSs, we calculate the other results by the two different algorithms based on MGPL-ETOPSIS and MGPL-VIKOR, respectively. Here, we let $\delta=0.5$ (Tables 14 and 15).

In Figures 1 and 2, we can find that the results based on MGPL-TOPSIS and MGPL-ETOPSIS are the same as follows. When $\lambda=1$, the ranking of $A_{i}(i=1,2, \ldots, 5)$ is " $A_{1}>A_{5}>A_{4}>A_{2}>A_{3}$." When $\lambda=2$, the ranking is " $A_{1}>A_{5}>A_{4}>A_{3}>A_{2}$," and when $\lambda=3,4, \ldots, 10$, the ranking is " $A_{5}>A_{1}>A_{4}>A_{3}>A_{2}$." The results based on MGPLVIKOR are as follows (Figure 3 ). When $\lambda=1, \lambda=2$, and $\lambda=3$, the ranking is " $A_{1}>A_{4}>A_{5}>A_{2}>A_{3}$," and when $\lambda=4,5, \ldots, 10$, the ranking is " $A_{1}>A_{5}>A_{4}>A_{3}>A_{2}$." The results based on PT are as follows. When $\lambda=1$ and 2 , the ranking is " $A_{5}>A_{1}>A_{2}>A_{4}>A_{3}$," and when $\lambda=3,4, \ldots, 10$, the ranking is " $A_{5}>A_{1}>A_{2}>A_{3}>A_{4}$."

5.3. Sensitivity Analysis. To calculate the sensitivity parameter $\lambda$, we take the algorithm's different parameters based on PT [29] and $\operatorname{rank} A_{i}(i=1,2, \ldots, 5)$. Then, the results are shown in Tables 16-19.

Tables 16-20 show that the results are as follows. When $\lambda=1$, the ranking of $A_{i} \quad(i=1,2, \ldots, 5)$ is " $A_{1}>A_{5}>A_{4}>A_{2}>A_{3}$." When $\lambda=2$, the ranking is " $A_{1}>A_{5}>A_{4}>A_{3}>A_{2}$," and when $\lambda=3,4, \ldots, 10$, the ranking is " $A_{5}>A_{1}>A_{4}>A_{3}>A_{2}$ " although the parameters $\theta, \alpha$, and $\beta$ are changed. Therefore, the larger the parameter $\lambda$, the ranking $A_{i}$ tends to be stable, which is not affected by the parameters' subjective psychological factors $\theta, \alpha$, and $\beta$. The definitions of distance measures between two PLTSs under a multigranular linguistic environment are scientifically presented in Section 3.

\section{The Extended TOPSIS Method}

There is a set of three alternatives $A=\left\{A_{1}, A_{2}, A_{3}\right\}$ and the weight vector $w=\left(w_{1}, w_{2}, w_{3}, w_{4}\right)^{T}$ of attribute vector $x=\left(x_{1}, x_{2}, x_{3}, x_{4}\right)^{T}$, where $0 \leq w_{j} \leq 1, \quad \sum_{j=1}^{n} w_{j}=1 \quad[10]$. The five DMs assess the three alternatives on four attributes by the multigranular linguistic set, which is $S=\left\{S_{0}=\right.$ none, $S_{1}=$ very low, $S_{2}=$ low, $S_{3}=$ medium, $S_{4}=$ high, $S_{5}=$ very high, $S_{6}=$ perfect $\}$ (Tables 21-25).

Step 1: collect the five DMs' evaluation information:

Their original decision matrices are shown in Tables 21-25. The probabilistic linguistic decision matrix and the normalized probabilistic linguistic decision matrix of the group are shown in Tables 26 and 27.

Step 2: calculate the weight vector of the attributes $x_{j}(j=1,2,3,4)$ :

$$
w=(0.2396,0.2340,0.1332,0.3931)^{T} .
$$

Step 3: determine the PLPIS $L^{+}$and the PLNIS $L^{-}$, respectively (Table 28 ).

Step 4: calculate the deviation degrees between each alternative and the PLPIS (PLNIS), respectively $(i=1,2,3)$ : 
TABLE 1: Evaluation information by $s_{5}$ (scoring data).

\begin{tabular}{lcccccccc}
\hline Alternative & $x_{1}$ & $x_{2}$ & $x_{3}$ & $x_{4}$ & $x_{5}$ & $x_{6}$ & $x_{7}$ \\
\hline$A_{1}$ & $S_{4.87}^{5}$ & $S_{5}^{5}$ & $S_{5}^{5}$ & $S_{5}^{5}$ & $S_{4.47}^{5}$ & $S_{4.63}^{5}$ & $S_{4.3}^{5}$ & $S_{4.83}^{5}$ \\
$A_{2}$ & $S_{4.79}^{5}$ & $S_{4.81}^{5}$ & $S_{4.75}^{5}$ & $S_{4.65}^{5}$ & $S_{4.02}^{5}$ & $S_{4.75}^{5}$ & $S_{4.64}^{5}$ \\
$A_{3}$ & $S_{4.33}^{5}$ & $S_{4.71}^{5}$ & $S_{4.67}^{5}$ & $S_{4.45}^{5}$ & $S_{4.39}^{5}$ & $S_{4.85}^{5}$ & $S_{4.24}^{5}$ \\
$A_{4}$ & $S_{4.48}^{5}$ & $S_{4.77}^{5}$ & $S_{4.55}^{5}$ & $S_{4.30}^{5}$ & $S_{4.39}^{5}$ & $S_{4.64}^{5}$ & $S_{4.47}^{5}$ \\
$A_{5}$ & $S_{4.40}^{5}$ & $S_{4.78}^{5}$ & $S_{4.61}^{5}$ & $S_{4.45}^{5}$ & $S_{4.16}^{5}$ & $S_{4.81}^{5}$ & $S_{4.27}^{5}$ & $S_{4.45}^{5}$ \\
\hline
\end{tabular}

TABLE 2: Evaluation information by $s_{7}$ (word-of-mouth data).

\begin{tabular}{lllllllll}
\hline Alternative & $x_{1}$ & $x_{2}$ & $x_{3}$ & $x_{4}$ & $x_{5}$ & $x_{6}$ & $x_{7}$ & $x_{8}$ \\
\hline$A_{1}$ & $S_{7}^{7}$ & $S_{7}^{7}$ & $S_{7}^{7}$ & - & $S_{7}^{7}$ & $S_{6}^{7}$ & - & $S_{7}^{7}$ \\
$A_{2}$ & $S_{5}^{7}$ & $S_{7}^{7}$ & $S_{6}^{7}$ & - & $S_{4}^{7}$ & $S_{7}^{7}$ & $S_{6}^{7}$ \\
$A_{3}$ & $S_{3}^{7}$ & $S_{5}^{7}$ & $S_{6}^{7}$ & $S_{1}^{7}$ & $S_{1}^{7}$ & $S_{7}^{7}$ & $S_{4}^{7}$ \\
$A_{4}$ & $S_{7}^{7}$ & $S_{3}^{7}$ & $S_{7}^{7}$ & $S_{1}^{7}$ & $S_{6}^{7}$ & $S_{6}^{7}$ & $S_{7}^{7}$ \\
$A_{5}$ & $S_{7}^{7}$ & - & $S_{7}^{7}$ & - & $S_{7}^{7}$ & $S_{7}^{7}$ & $S_{6}^{7}$ \\
\hline
\end{tabular}

TABLE 3: Evaluation information by $s_{9}$ (forum reviews data).

\begin{tabular}{llllllll}
\hline Alternative & $x_{1}$ & $x_{2}$ & $x_{3}$ & $x_{4}$ & $x_{5}$ & $x_{6}$ & $x_{7}$ \\
\hline$A_{1}$ & $S_{9}^{9}$ & $S_{8}^{9}$ & $S_{7}^{9}$ & $S_{3}^{9}$ & $S_{7}^{9}$ & $S_{8}^{9}$ & $S_{5}^{9}$ \\
$A_{2}$ & $S_{7}^{9}$ & $S_{8}^{9}$ & $S_{7}^{9}$ & - & $S_{5}^{9}$ & $S_{2}^{9}$ & $S_{9}^{9}$ \\
$A_{3}$ & $S_{5}^{9}$ & $S_{6}^{9}$ & $S_{5}^{9}$ & $S_{2}^{9}$ & $S_{3}^{9}$ & $S_{9}^{9}$ & $S_{5}^{9}$ \\
$A_{4}$ & $S_{8}^{9}$ & $S_{4}^{9}$ & $S_{8}^{9}$ & $S_{3}^{9}$ & $S_{4}^{9}$ & $S_{5}^{9}$ & $S_{9}^{9}$ \\
$A_{5}$ & $S_{9}^{9}$ & $S_{1}^{9}$ & $S_{9}^{9}$ & - & $S_{9}^{9}$ & $S_{8}^{9}$ & $S_{7}^{9}$ \\
\hline
\end{tabular}

Table 4: The linguistic evaluation matrix.

\begin{tabular}{|c|c|c|c|c|}
\hline Alternative & $x_{1}$ & $x_{2}$ & $x_{3}$ & $x_{4}$ \\
\hline$A_{1}$ & $\left\{S_{4.87}^{5}, S_{7}^{7}, S_{9}^{9}\right\}$ & $\left\{S_{5}^{5}, S_{7}^{7}, S_{8}^{9}\right\}$ & $\left\{S_{5}^{5}, S_{7}^{7}, S_{7}^{9}\right\}$ & $\left\{S_{5}^{5}, S_{3}^{9}\right\}$ \\
\hline$A_{2}$ & $\left\{S_{4.79}^{5}, S_{5}^{7}, S_{7}^{9}\right\}$ & $\left\{S_{4.81}^{5}, S_{7}^{7}, S_{8}^{9}\right\}$ & $\left\{S_{4.75}^{5}, S_{6}^{7}, S_{7}^{9}\right\}$ & $\left\{S_{4.65}^{5}\right\}$ \\
\hline$A_{3}$ & $\left\{S_{4.33}^{5}, S_{3}^{7}, S_{5}^{9}\right\}$ & $\left\{S_{4.71}^{5}, S_{5}^{7}, S_{6}^{9}\right\}$ & $\left\{S_{4.67}^{5}, S_{6}^{7}, S_{5}^{9}\right\}$ & $\left\{S_{4.45}^{5}, S_{1}^{7}, S_{2}^{9}\right\}$ \\
\hline$A_{4}$ & $\left\{S_{4.48}^{5}, S_{7}^{7}, S_{8}^{9}\right\}$ & $\left\{S_{4.77}^{5}, S_{3}^{7}, S_{4}^{9}\right\}$ & $\left\{S_{4.55}^{5}, S_{7}^{7}, S_{8}^{9}\right\}$ & $\left\{S_{4,3}^{5}, S_{1}^{7}, S_{3}^{9}\right\}$ \\
\hline$A_{5}$ & $\left\{S_{4.4}^{5}, S_{7}^{7}, S_{9}^{9}\right\}$ & $\left\{S_{4.78}^{5}, S_{1}^{9}\right\}$ & $\left\{S_{4.61}^{5}, S_{7}^{7}, S_{9}^{9}\right\}$ & $\left\{S_{4.45}^{5}\right\}$ \\
\hline Alternative & $x_{5}$ & $x_{6}$ & $x_{7}$ & $x_{8}$ \\
\hline$A_{1}$ & $\left\{S_{4.47}^{5}, S_{7}^{7}, S_{7}^{9}\right\}$ & $\left\{S_{4.63}^{5}, S_{6}^{7}, S_{8}^{9}\right\}$ & $\left\{S_{4.3}^{5}, S_{4}^{7}, S_{5}^{9}\right\}$ & $\left\{S_{4.83}^{5}, S_{7}^{7}, S_{9}^{9}\right\}$ \\
\hline$A_{2}$ & $\left\{S_{4.02}^{5}, S_{4}^{7}, S_{5}^{9}\right\}$ & $\left\{S_{4.75}^{5}, S_{7}^{7}, S_{2}^{9}\right\}$ & $\left\{S_{5.64}^{5}, S_{6}^{7}, S_{1}^{9}\right\}$ & $\left\{S_{4.75}^{5}, S_{6}^{7}, S_{3}^{9}\right\}$ \\
\hline$A_{3}$ & $\left\{S_{4.39}^{5}, S_{1}^{7}, S_{3}^{9}\right\}$ & $\left\{S_{4.85}^{5}, S_{7}^{7}, S_{9}^{9}\right\}$ & $\left\{S_{4.24}^{5}, S_{4}^{7}, S_{5}^{9}\right\}$ & $\left\{S_{4.75}^{5}, S_{4}^{7}, S_{4}^{9}\right\}$ \\
\hline$A_{4}$ & $\left\{S_{4.39}^{5}, S_{6}^{7}, S_{4}^{9}\right\}$ & $\left\{S_{4.64}^{5}, S_{6}^{7}, S_{5}^{9}\right\}$ & $\left\{S_{4.47}^{5}, S_{7}^{7}, S_{9}^{9}\right\}$ & $\left\{S_{4.55}^{5}, S_{5}^{7}, S_{7}^{9}\right\}$ \\
\hline$A_{5}$ & $\left\{S_{4.16}^{5}, S_{7}^{7}, S_{9}^{9}\right\}$ & $\left\{S_{4.81}^{5}, S_{7}^{7}, S_{8}^{9}\right\}$ & $\left\{S_{4.27}^{5}, S_{6}^{7}, S_{7}^{9}\right\}$ & $\left\{S_{4.45}^{5}, S_{7}^{7}, S_{9}^{9}\right\}$ \\
\hline
\end{tabular}

TABle 5: The probabilistic linguistic evaluation matrix.

\begin{tabular}{lcccc}
\hline Alternative & $x_{1}$ & $x_{2}$ & $x_{3}$ & $x_{4}$ \\
\hline$A_{1}$ & $\left\{S_{4.87}^{5}(1 / 3), S_{7}^{7}(1 / 3), S_{9}^{9}(1 / 3)\right\}$ & $\left\{S_{5}^{5}(1 / 3), S_{7}^{7}(1 / 3), S_{8}^{9}(1 / 3)\right\}$ & $\left\{S_{5}^{5}(1 / 3), S_{7}^{7}(1 / 3), S_{7}^{9}(1 / 3)\right\}$ & $\left\{S_{5}^{5}(1 / 3), S_{1}^{7}(1 / 3), S_{3}^{9}(1 / 3)\right\}$ \\
$A_{2}$ & $\left\{S_{4.79}^{5}(1 / 3), S_{5}^{7}(1 / 3), S_{7}^{9}(1 / 3)\right\}$ & $\left\{S_{4.81}^{5}(1 / 3), S_{7}^{7}(1 / 3), S_{8}^{9}(1 / 3)\right\}$ & $\left\{S_{4.75}^{5}(1 / 3), S_{6}^{7}(1 / 3), S_{7}^{9}(1 / 3)\right\}$ & $\left\{S_{4.65}^{5}(1 / 3), S_{1}^{7}(1 / 3), S_{2}^{9}(1 / 3)\right\}$ \\
$A_{3}$ & $\left\{S_{4.33}^{5}(1 / 3), S_{3}^{7}(1 / 3), S_{5}^{9}(1 / 3)\right\}$ & $\left\{S_{4.71}^{5}(1 / 3), S_{5}^{7}(1 / 3), S_{6}^{9}(1 / 3)\right\}$ & $\left\{S_{4.67}^{5}(1 / 3), S_{6}^{7}(1 / 3), S_{5}^{9}(1 / 3)\right\}$ & $\left\{S_{4.45}^{5}(1 / 3), S_{1}^{7}(1 / 3), S_{2}^{9}(1 / 3)\right\}$ \\
$A_{4}$ & $\left\{S_{4.48}^{5}(1 / 3), S_{7}^{7}(1 / 3), S_{8}^{9}(1 / 3)\right\}$ & $\left\{S_{4.77}^{5}(1 / 3), S_{3}^{7}(1 / 3), S_{4}^{9}(1 / 3)\right\}$ & $\left\{S_{4.55}^{5}(1 / 3), S_{7}^{7}(1 / 3), S_{8}^{9}(1 / 3)\right\}$ & $\left\{S_{4.3}^{5}(1 / 3), S_{1}^{7}(1 / 3), S_{3}^{9}(1 / 3)\right\}$ \\
$A_{5}$ & $\left\{S_{4.4}^{5}(1 / 3), S_{7}^{7}(1 / 3), S_{9}^{9}(1 / 3)\right\}$ & $\left\{S_{4.78}^{5}(1 / 3), S_{3}^{7}(1 / 3), S_{1}^{9}(1 / 3)\right\}$ & $\left\{S_{4.61}^{5}(1 / 3), S_{7}^{7}(1 / 3), S_{9}^{9}(1 / 3)\right\}$ & $\left\{S_{4.45}^{5}(1 / 3), S_{1}^{7}(1 / 3), S_{2}^{9}(1 / 3)\right\}$ \\
Alternative & $x_{5}$ & $x_{6}$ & $x_{7}$ & $x_{8}$ \\
$A_{1}$ & $\left\{S_{4.47}^{5}(1 / 3), S_{7}^{7}(1 / 3), S_{7}^{9}(1 / 3)\right\}$ & $\left\{S_{4.63}^{5}(1 / 3), S_{6}^{7}(1 / 3), S_{8}^{9}(1 / 3)\right\}$ & $\left\{S_{4.3}^{5}(1 / 3), S_{4}^{7}(1 / 3), S_{5}^{9}(1 / 3)\right\}$ & $\left\{S_{4.83}^{5}(1 / 3), S_{7}^{7}(1 / 3), S_{9}^{9}(1 / 3)\right\}$ \\
$A_{2}$ & $\left\{S_{4.02}^{5}(1 / 3), S_{4}^{7}(1 / 3), S_{5}^{9}(1 / 3)\right\}$ & $\left\{S_{4.75}^{5}(1 / 3), S_{7}^{7}(1 / 3), S_{2}^{9}(1 / 3)\right\}$ & $\left\{S_{5.64}^{5}(1 / 3), S_{6}^{7}(1 / 3), S_{1}^{9}(1 / 3)\right\}$ & $\left\{S_{4.75}^{5}(1 / 3), S_{6}^{7}(1 / 3), S_{3}^{9}(1 / 3)\right\}$ \\
$A_{3}$ & $\left\{S_{4.39}^{5}(1 / 3), S_{1}^{7}(1 / 3), S_{3}^{9}(1 / 3)\right\}$ & $\left\{S_{4.85}^{5}(1 / 3), S_{7}^{7}(1 / 3), S_{9}^{9}(1 / 3)\right\}$ & $\left\{S_{4.24}^{5}(1 / 3), S_{4}^{7}(1 / 3), S_{5}^{9}(1 / 3)\right\}$ & $\left\{S_{4.75}^{5}(1 / 3), S_{4}^{7}(1 / 3), S_{4}^{9}(1 / 3)\right\}$ \\
$A_{4}$ & $\left\{S_{4.39}^{5}(1 / 3), S_{6}^{7}(1 / 3), S_{4}^{9}(1 / 3)\right\}$ & $\left\{S_{4.64}^{5}(1 / 3), S_{6}^{7}(1 / 3), S_{5}^{9}(1 / 3)\right\}$ & $\left\{S_{4.47}^{5}(1 / 3), S_{7}^{7}(1 / 3), S_{9}^{9}(1 / 3)\right\}$ & $\left\{S_{4.55}^{5}(1 / 3), S_{5}^{7}(1 / 3), S_{7}^{9}(1 / 3)\right\}$ \\
$A_{5}$ & $\left\{S_{4.16}^{5}(1 / 3), S_{7}^{7}(1 / 3), S_{9}^{9}(1 / 3)\right\}$ & $\left\{S_{4.81}^{5}(1 / 3), S_{7}^{7}(1 / 3), S_{8}^{9}(1 / 3)\right\}$ & $\left\{S_{4.27}^{5}(1 / 3), S_{6}^{7}(1 / 3), S_{7}^{9}(1 / 3)\right\}$ & $\left\{S_{4.45}^{5}(1 / 3), S_{7}^{7}(1 / 3), S_{9}^{9}(1 / 3)\right\}$ \\
\hline
\end{tabular}




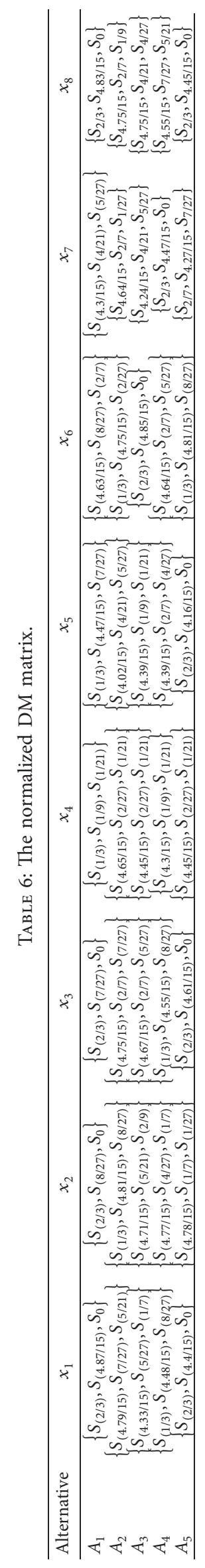


Table 7: The weights of the attributes.

\begin{tabular}{lcccccccc}
\hline Attribute & $x_{1}$ & $x_{2}$ & $x_{3}$ & $x_{4}$ & $x_{5}$ & $x_{6}$ & $x_{7}$ & $x_{8}$ \\
\hline Weight & 0.0921 & 0.1265 & 0.0807 & 0.2466 & 0.1350 & 0.0895 & 0.1262 & 0.1034 \\
\hline
\end{tabular}

TABLE 8: The normalized PLPIS.

\begin{tabular}{lcccc}
\hline Attribute & $x_{1}$ & $x_{2}$ & $x_{3}$ & $x_{4}$ \\
\hline PLPIS & $(0.6667,0.3247,0.2963)$ & $(0.6667,0.3207,0.2963)$ & $(0.6667,0.3073,0.2963)$ & $(0.3333,0.1111,0.0476)$ \\
\hline Attribute & $x_{5}$ & $x_{6}$ & $x_{7}$ & $x_{8}$ \\
\hline PLPIS & $(0.6667,0.2980,0.2593)$ & $(0.6667,0.3233,0.2963)$ & $(0.6667,0.2980,0.2593)$ & $(0.6667,0.3220,0.2381)$ \\
\hline
\end{tabular}

TABle 9: The normalized PLNIS.

\begin{tabular}{lcccc}
\hline Attribute & $x_{1}$ & $x_{2}$ & $x_{3}$ & $x_{4}$ \\
\hline PLNIS & $(0.2887,0.1852,0.2963)$ & $(0.3140,0.1429,0.2963)$ & $(0.3113,0.2593,0.2963)$ & $(0.2867,0.0741,0.0476)$ \\
\hline Attribute & $x_{5}$ & $x_{6}$ & $x_{7}$ & $x_{8}$ \\
\hline PLNIS & $(0.2680,0.1111,0.2593)$ & $(0.3087,0.2857,0.2963)$ & $(0.2827,0.1905,0.2593)$ & $(0.3033,0.1905,0.2381)$ \\
\hline
\end{tabular}

TAвLE 10: The results of $d\left(A_{i}, L^{-}\right)$.

\begin{tabular}{|c|c|c|c|c|c|}
\hline Alternative & $A_{1}$ & $A_{2}$ & $A_{3}$ & $A_{4}$ & $A_{5}$ \\
\hline$\lambda=1$ & 0.1238 & 0.0549 & 0.0549 & 0.0549 & 0.0549 \\
\hline$\lambda=2$ & 0.1810 & 0.0846 & 0.1036 & 0.1168 & 0.1867 \\
\hline$\lambda=3$ & 0.2160 & 0.1071 & 0.1412 & 0.1551 & 0.2236 \\
\hline$\lambda=4$ & 0.2395 & 0.1241 & 0.1702 & 0.1859 & 0.2481 \\
\hline$\lambda=5$ & 0.2564 & 0.1372 & 0.1928 & 0.2106 & 0.2658 \\
\hline$\lambda=6$ & 0.2692 & 0.1473 & 0.2107 & 0.2304 & 0.2795 \\
\hline$\lambda=7$ & 0.2793 & 0.1554 & 0.2252 & 0.2466 & 0.2904 \\
\hline$\lambda=8$ & 0.2874 & 0.1619 & 0.2372 & 0.2599 & 0.2993 \\
\hline$\lambda=9$ & 0.2941 & 0.1673 & 0.2472 & 0.2709 & 0.3068 \\
\hline$\lambda=10$ & 0.2998 & 0.1719 & 0.2557 & 0.2803 & 0.3132 \\
\hline
\end{tabular}

TABLe 11: The results of $d\left(A_{i}, L^{+}\right)$.

\begin{tabular}{|c|c|c|c|c|c|}
\hline Alternative & $A_{1}$ & $A_{2}$ & $A_{3}$ & $A_{4}$ & $A_{5}$ \\
\hline$\lambda=1$ & 0.0905 & 0.1299 & 0.1484 & 0.1155 & 0.1055 \\
\hline$\lambda=2$ & 0.1626 & 0.1926 & 0.1999 & 0.1805 & 0.1704 \\
\hline$\lambda=3$ & 0.2039 & 0.2309 & 0.2344 & 0.2191 & 0.2075 \\
\hline$\lambda=4$ & 0.2302 & 0.2557 & 0.2583 & 0.2444 & 0.2313 \\
\hline$\lambda=5$ & 0.2486 & 0.2729 & 0.2754 & 0.2621 & 0.2483 \\
\hline$\lambda=6$ & 0.2622 & 0.2856 & 0.2882 & 0.2751 & 0.2612 \\
\hline$\lambda=7$ & 0.2729 & 0.2954 & 0.2981 & 0.2852 & 0.2715 \\
\hline$\lambda=8$ & 0.2815 & 0.3033 & 0.3059 & 0.2931 & 0.2801 \\
\hline$\lambda=9$ & 0.2888 & 0.3098 & 0.3122 & 0.2996 & 0.2873 \\
\hline$\lambda=10$ & 0.2949 & 0.3153 & 0.3175 & 0.3050 & 0.2936 \\
\hline
\end{tabular}

TABle 12: The closeness coefficient $\mathrm{CD}_{i}$.

\begin{tabular}{|c|c|c|c|c|c|}
\hline Alternative & $A_{1}$ & $A_{2}$ & $A_{3}$ & $A_{4}$ & $A_{5}$ \\
\hline$\lambda=1$ & 0.5776 & 0.2969 & 0.2680 & 0.3699 & 0.5366 \\
\hline$\lambda=2$ & 0.5268 & 0.3053 & 0.3414 & 0.3928 & 0.5228 \\
\hline$\lambda=3$ & 0.5144 & 0.3168 & 0.3760 & 0.4145 & 0.5186 \\
\hline$\lambda=4$ & 0.5099 & 0.3268 & 0.3972 & 0.4320 & 0.5175 \\
\hline$\lambda=5$ & 0.5078 & 0.3345 & 0.4118 & 0.4455 & 0.5171 \\
\hline$\lambda=6$ & 0.5066 & 0.3403 & 0.4223 & 0.4558 & 0.5169 \\
\hline$\lambda=7$ & 0.5058 & 0.3447 & 0.4304 & 0.4637 & 0.5168 \\
\hline$\lambda=8$ & 0.5052 & 0.3481 & 0.4367 & 0.4699 & 0.5166 \\
\hline$\lambda=9$ & 0.5046 & 0.3507 & 0.4419 & 0.4749 & 0.5164 \\
\hline$\lambda=10$ & 0.5041 & 0.3528 & 0.4461 & 0.4789 & 0.5162 \\
\hline
\end{tabular}


TABLE 13: The ranking of $A_{i}$.

\begin{tabular}{lr}
\hline Distance parameter & Rank \\
\hline$\lambda=1$ & $A_{1}>A_{5}>A_{4}>A_{2}>A_{3}$ \\
$\lambda=2$ & $A_{1}>A_{5}>A_{4}>A_{3}>A_{2}$ \\
$\lambda=3$ & $A_{5}>A_{1}>A_{4}>A_{3}>A_{2}$ \\
$\lambda=4$ & $A_{5}>A_{1}>A_{4}>A_{3}>A_{2}$ \\
$\lambda=5$ & $A_{5}>A_{1}>A_{4}>A_{3}>A_{2}$ \\
$\lambda=6$ & $A_{5}>A_{1}>A_{4}>A_{3}>A_{2}$ \\
$\lambda=7$ & $A_{5}>A_{1}>A_{4}>A_{3}>A_{2}$ \\
$\lambda=8$ & $A_{5}>A_{1}>A_{4}>A_{3}>A_{2}$ \\
$\lambda=9$ & $A_{5}>A_{1}>A_{4}>A_{3}>A_{2}$ \\
$\lambda=10$ & $A_{5}>A_{1}>A_{4}>A_{3}>A_{2}$ \\
\hline
\end{tabular}

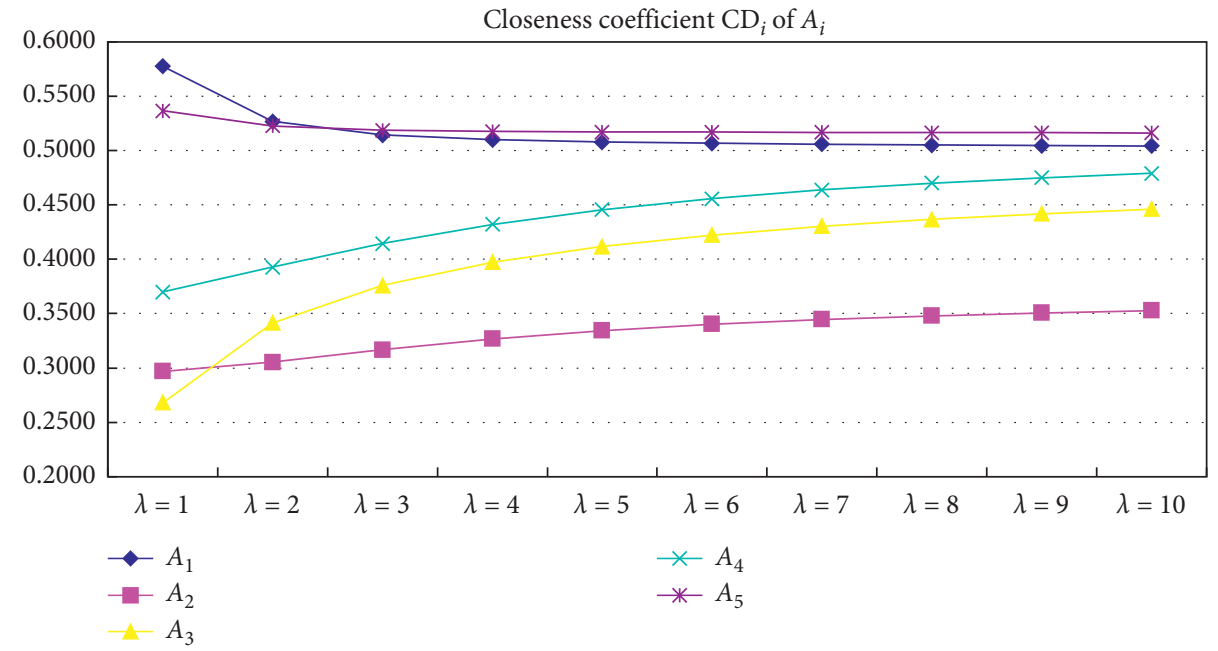

Figure 1: $\mathrm{CD}_{i}$ based on MGPL-TOPSIS.

TABle 14: The compromise index $\mathrm{CI}_{i}$ based on MGPL-ETOPSIS.

\begin{tabular}{|c|c|c|c|c|c|}
\hline Alternative & $A_{1}$ & $A_{2}$ & $A_{3}$ & $A_{4}$ & $A_{5}$ \\
\hline$\lambda=1$ & -0.0005 & -0.9926 & -1.2005 & -0.7282 & -0.1789 \\
\hline$\lambda=2$ & -0.0304 & -0.7314 & -0.6742 & -0.4844 & -0.0481 \\
\hline$\lambda=3$ & -0.0340 & -0.6535 & -0.5179 & -0.3809 & -0.0178 \\
\hline$\lambda=4$ & -0.0347 & -0.6103 & -0.4359 & -0.3123 & -0.0050 \\
\hline$\lambda=5$ & -0.0363 & -0.5830 & -0.3839 & -0.2633 & 0.0003 \\
\hline$\lambda=6$ & -0.0407 & -0.5663 & -0.3495 & -0.2289 & 0.0000 \\
\hline$\lambda=7$ & -0.0434 & -0.5531 & -0.3223 & -0.2013 & -0.0003 \\
\hline$\lambda=8$ & -0.0449 & -0.5418 & -0.2996 & -0.1783 & 0.0000 \\
\hline$\lambda=9$ & -0.0463 & -0.5329 & -0.2810 & -0.1597 & -0.0001 \\
\hline$\lambda=10$ & -0.0471 & -0.5251 & -0.2649 & -0.1438 & 0.0001 \\
\hline
\end{tabular}

TABLE 15: The compromise index $\mathrm{MC}_{i}$ based on MGPL-VIKOR.

\begin{tabular}{|c|c|c|c|c|c|}
\hline Alternative & $A_{1}$ & $A_{2}$ & $A_{3}$ & $A_{4}$ & $A_{5}$ \\
\hline$\lambda=1$ & 0.9243 & 0.4534 & 0.0000 & 0.7823 & 0.5470 \\
\hline$\lambda=2$ & 0.8473 & 0.2973 & 0.0000 & 0.6797 & 0.4548 \\
\hline$\lambda=3$ & 0.9238 & 0.1604 & 0.0000 & 0.6262 & 0.5279 \\
\hline$\lambda=4$ & 1.0000 & 0.0459 & 0.2072 & 0.5743 & 0.6898 \\
\hline$\lambda=5$ & 1.0000 & 0.0427 & 0.3241 & 0.5230 & 0.7447 \\
\hline$\lambda=6$ & 1.0000 & 0.0407 & 0.3717 & 0.5021 & 0.7564 \\
\hline$\lambda=7$ & 1.0000 & 0.0390 & 0.3931 & 0.4922 & 0.7599 \\
\hline$\lambda=8$ & 1.0000 & 0.0374 & 0.4032 & 0.4867 & 0.7625 \\
\hline$\lambda=9$ & 1.0000 & 0.0360 & 0.4081 & 0.4834 & 0.7644 \\
\hline$\lambda=10$ & 1.0000 & 0.0347 & 0.4105 & 0.4811 & 0.7659 \\
\hline
\end{tabular}




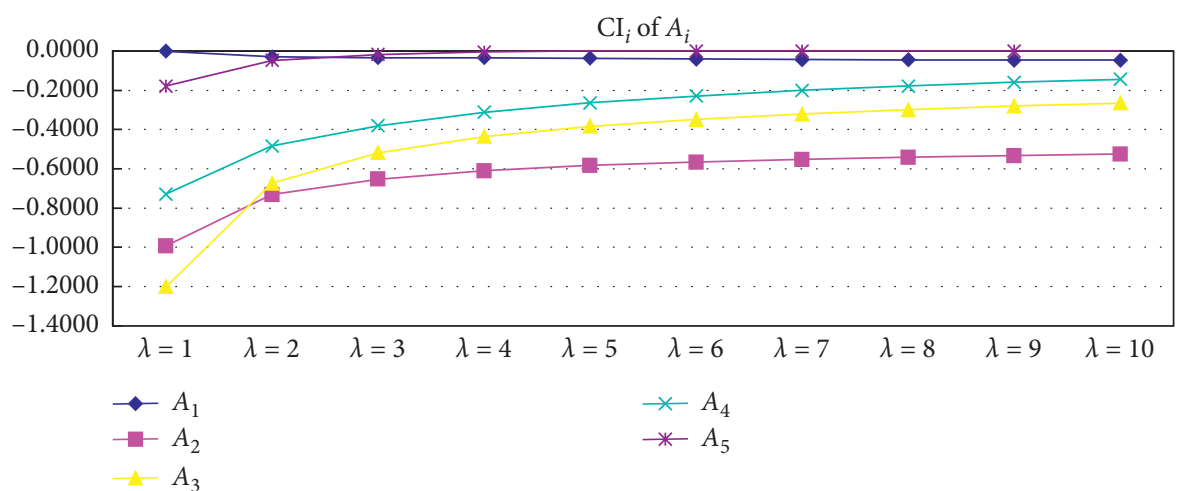

FIgURE 2: $\mathrm{CI}_{i}$ based on MGPL-ETOPSIS.

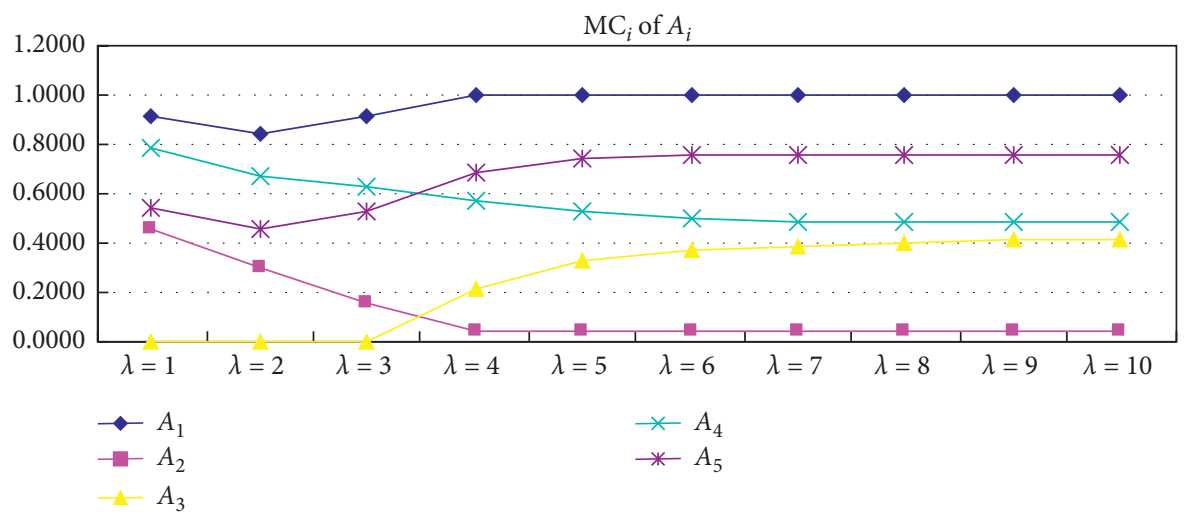

Figure 3: The $\mathrm{MC}_{i}$ based on MGPL-VIKOR.

TABLE 16: The ration $\mathrm{CP}_{i}$ based on PT $(\alpha=0.85, \theta=4.1$, and $\beta=0.85)$.

\begin{tabular}{lccccr}
\hline Alternative & $A_{1}$ & $A_{2}$ & $A_{3}$ & $A_{4}$ & $A_{5}$ \\
\hline$\lambda=1$ & 0.3130 & 0.1145 & 0.1076 & 0.1382 & 0.2853 \\
$\lambda=2$ & 0.2409 & 0.1109 & 0.1195 & 0.1283 & 0.2355 \\
$\lambda=3$ & 0.2203 & 0.1094 & 0.1209 & 0.1247 & 0.2222 \\
$\lambda=4$ & 0.2115 & 0.1085 & 0.1205 & 0.1230 & 0.2168 \\
$\lambda=5$ & 0.2071 & 0.1080 & 0.1199 & 0.1221 & 0.2141 \\
$\lambda=6$ & 0.2045 & 0.1077 & 0.1194 & 0.1217 & 0.2127 \\
$\lambda=7$ & 0.2029 & 0.1074 & 0.1190 & 0.1214 & 0.2118 \\
$\lambda=8$ & 0.2019 & 0.1072 & 0.1188 & 0.1213 & 0.2112 \\
$\lambda=9$ & 0.2012 & 0.1071 & 0.1186 & 0.1212 & 0.2109 \\
$\lambda=10$ & 0.2006 & 0.1070 & 0.1184 & 0.1211 & 0.2106 \\
\hline
\end{tabular}

TABLE 17: The ration $\mathrm{CP}_{i}$ based on PT $(\alpha=0.88, \theta=2.25$, and $\beta=0.88)$.

\begin{tabular}{lccccc}
\hline Alternative & $A_{1}$ & $A_{2}$ & $A_{3}$ & $A_{4}$ & $A_{5}$ \\
\hline$\lambda=1$ & 0.5783 & 0.2036 & 0.1921 & 0.2487 & 0.5267 \\
$\lambda=2$ & 0.4407 & 0.1970 & 0.2136 & 0.2298 & 0.4314 \\
$\lambda=3$ & 0.4015 & 0.1943 & 0.2161 & 0.2230 & 0.4060 \\
$\lambda=4$ & 0.3850 & 0.1928 & 0.2152 & 0.2198 & 0.3958 \\
$\lambda=5$ & 0.3766 & 0.1918 & 0.2141 & 0.2182 & 0.3908 \\
$\lambda=6$ & 0.3717 & 0.1912 & 0.2131 & 0.2173 & 0.3880 \\
$\lambda=7$ & 0.3687 & 0.1907 & 0.2124 & 0.2168 & 0.3863 \\
$\lambda=8$ & 0.3667 & 0.1904 & 0.2119 & 0.2165 & 0.3852 \\
$\lambda=9$ & 0.3654 & 0.1901 & 0.2116 & 0.2164 & 0.3845 \\
$\lambda=10$ & 0.3644 & 0.1899 & 0.2113 & 0.2163 & 0.3841 \\
\hline
\end{tabular}


TABLe 18: The ration $\mathrm{CP}_{i}$ based on PT $(\alpha=0.89, \theta=2.25$, and $\beta=0.92)$.

\begin{tabular}{|c|c|c|c|c|c|}
\hline Alternative & $A_{1}$ & $A_{2}$ & $A_{3}$ & $A_{4}$ & $A_{5}$ \\
\hline$\lambda=1$ & 0.6189 & 0.2134 & 0.2008 & 0.2625 & 0.5625 \\
\hline$\lambda=2$ & 0.4642 & 0.2047 & 0.2223 & 0.2400 & 0.4549 \\
\hline$\lambda=3$ & 0.4202 & 0.2010 & 0.2240 & 0.2316 & 0.4259 \\
\hline$\lambda=4$ & 0.4017 & 0.1990 & 0.2226 & 0.2277 & 0.4140 \\
\hline$\lambda=5$ & 0.3921 & 0.1977 & 0.2211 & 0.2257 & 0.4081 \\
\hline$\lambda=6$ & 0.3866 & 0.1968 & 0.2198 & 0.2245 & 0.4047 \\
\hline$\lambda=7$ & 0.3831 & 0.1962 & 0.2189 & 0.2238 & 0.4026 \\
\hline$\lambda=8$ & 0.3808 & 0.1958 & 0.2183 & 0.2234 & 0.4013 \\
\hline$\lambda=9$ & 0.3792 & 0.1954 & 0.2178 & 0.2231 & 0.4004 \\
\hline$\lambda=10$ & 0.3780 & 0.1952 & 0.2174 & 0.2229 & 0.3997 \\
\hline
\end{tabular}

Table 19: The ration $C_{i}(\alpha=0.725, \theta=2.04$, and $\beta=0.717)$.

\begin{tabular}{|c|c|c|c|c|c|}
\hline Alternative & $A_{1}$ & $A_{2}$ & $A_{3}$ & $A_{4}$ & $A_{5}$ \\
\hline$\lambda=1$ & 0.5861 & 0.2517 & 0.2342 & 0.2894 & 0.5353 \\
\hline$\lambda=2$ & 0.4721 & 0.2452 & 0.2581 & 0.2745 & 0.4575 \\
\hline$\lambda=3$ & 0.4385 & 0.2424 & 0.2614 & 0.2688 & 0.4365 \\
\hline$\lambda=4$ & 0.4242 & 0.2408 & 0.2610 & 0.2662 & 0.4281 \\
\hline$\lambda=5$ & 0.4169 & 0.2398 & 0.2602 & 0.2648 & 0.4240 \\
\hline$\lambda=6$ & 0.4127 & 0.2392 & 0.2595 & 0.2641 & 0.4217 \\
\hline$\lambda=7$ & 0.4101 & 0.2387 & 0.2589 & 0.2637 & 0.4204 \\
\hline$\lambda=8$ & 0.4083 & 0.2384 & 0.2585 & 0.2635 & 0.4742 \\
\hline$\lambda=9$ & 0.4072 & 0.2381 & 0.2582 & 0.2634 & 0.4190 \\
\hline$\lambda=10$ & 0.4063 & 0.2379 & 0.2580 & 0.2633 & 0.4187 \\
\hline
\end{tabular}

TABle 20: The ranking of $A_{i}$.

\begin{tabular}{|c|c|c|c|}
\hline Algorithm & Parameter & & Rank \\
\hline PT & $\begin{array}{c}\alpha=0.85, \theta=4.1, \beta=0.85 \\
\alpha=0.88, \theta=2.25, \beta=0.88 \\
\alpha=0.89, \theta=2.25, \beta=0.92 \\
\alpha=0.725, \theta=2.04, \beta=0.717\end{array}$ & $\begin{aligned} \lambda & =1 \\
\lambda & =2 \\
\lambda & =3 \\
\lambda & =4 \\
\lambda & =5 \\
\lambda & =6 \\
\lambda & =7 \\
\lambda & =8 \\
\lambda & =9 \\
\lambda & =10\end{aligned}$ & $\begin{array}{l}A_{1}>A_{5}>A_{4}>A_{2}>A_{3} \\
A_{1}>A_{5}>A_{4}>A_{3}>A_{2} \\
A_{5}>A_{1}>A_{4}>A_{3}>A_{2} \\
A_{5}>A_{1}>A_{4}>A_{3}>A_{2} \\
A_{5}>A_{1}>A_{4}>A_{3}>A_{2} \\
A_{5}>A_{1}>A_{4}>A_{3}>A_{2} \\
A_{5}>A_{1}>A_{4}>A_{3}>A_{2} \\
A_{5}>A_{1}>A_{4}>A_{3}>A_{2} \\
A_{5}>A_{1}>A_{4}>A_{3}>A_{2} \\
A_{5}>A_{1}>A_{4}>A_{3}>A_{2}\end{array}$ \\
\hline
\end{tabular}

TABLE 21: The linguistic decision matrix provided by the first DM.

\begin{tabular}{lllll}
\hline Alternative & $x_{1}$ & $x_{2}$ & $x_{3}$ & $x_{4}$ \\
\hline$A_{1}$ & $S_{3}$ & $S_{4}$ & $S_{5}$ & $S_{4}$ \\
$A_{2}$ & $S_{2}$ & $S_{3}$ & $S_{1}$ & $S_{2}$ \\
$A_{3}$ & $S_{4}$ & $S_{3}$ & - & $S_{5}$ \\
\hline
\end{tabular}

TABLE 22: The linguistic decision matrix provided by the second DM.

\begin{tabular}{lllll}
\hline Alternative & $x_{1}$ & $x_{2}$ & $x_{3}$ & $x_{4}$ \\
\hline$A_{1}$ & $S_{4}$ & $S_{2}$ & $S_{4}$ & \\
$A_{2}$ & $S_{3}$ & $S_{1}$ & $-S_{5}$ & \\
$A_{3}$ & $S_{5}$ & $S_{3}$ & $S_{4}$ & $S_{3}$ \\
\hline
\end{tabular}


TABLe 23: The linguistic decision matrix provided by the third DM.

\begin{tabular}{lllll}
\hline Alternative & $x_{1}$ & $x_{2}$ & $x_{3}$ & $x_{4}$ \\
\hline$A_{1}$ & $S_{4}$ & - & $S_{4}$ & $S_{4}$ \\
$A_{2}$ & $S_{3}$ & $S_{2}$ & $S_{5}$ & $S_{3}$ \\
$A_{3}$ & $S_{4}$ & $S_{3}$ & $S_{1}$ & $S_{5}$ \\
\hline
\end{tabular}

TABle 24: The linguistic decision matrix provided by the fourth DM.

\begin{tabular}{lllll}
\hline Alternative & $x_{1}$ & $x_{2}$ & $x_{3}$ & $x_{4}$ \\
\hline$A_{1}$ & $S_{4}$ & $S_{4}$ & $S_{5}$ & $S_{3}$ \\
$A_{2}$ & $S_{5}$ & $S_{2}$ & $S_{4}$ & - \\
$A_{3}$ & $S_{3}$ & $S_{2}$ & $S_{4}$ & $S_{4}$ \\
\hline
\end{tabular}

TABle 25: The linguistic decision matrix provided by the fifth DM.

\begin{tabular}{lllll}
\hline Alternative & $x_{1}$ & $x_{2}$ & $x_{3}$ & $x_{4}$ \\
\hline$A_{1}$ & $S_{3}$ & $S_{4}$ & $S_{2}$ & $S_{5}$ \\
$A_{2}$ & $S_{3}$ & $S_{3}$ & $S_{4}$ & $S_{2}$ \\
$A_{3}$ & $S_{3}$ & - & $S_{5}$ & $S_{4}$ \\
\hline
\end{tabular}

TABLE 26: The probabilistic linguistic decision matrix of the group.

\begin{tabular}{lcccc}
\hline Attributes & $x_{1}$ & $x_{2}$ & $x_{3}$ & $x_{4}$ \\
\hline$A_{1}$ & $\left\{S_{3}(0.4), S_{4}(0.6)\right\}$ & $\left\{S_{4}(0.6), S_{2}(0.2)\right\}$ & $\left\{S_{5}(0.4), S_{2}(0.2), S_{4}(0.4)\right\}$ & $\left\{S_{4}(0.4), S_{3}(0.2), S_{5}(0.4)\right\}$ \\
$A_{2}$ & $\left\{S_{2}(0.2), S_{3}(0.6), S_{5}(0.2)\right\}$ & $\left\{S_{3}(0.4), S_{1}(0.2), S_{2}(0.4)\right\}$ & $\left\{S_{1}(0.2), S_{5}(0.2), S_{4}(0.4)\right\}$ & $\left\{S_{3}(0.4), S_{2}(0.4)\right\}$ \\
$A_{3}$ & $\left\{S_{4}(0.4), S_{3}(0.4), S_{5}(0.2)\right\}$ & $\left\{S_{3}(0.6), S_{2}(0.2)\right\}$ & $\left\{S_{1}(0.2), S_{5}(0.2), S_{4}(0.4)\right\}$ & $\left\{S_{4}(0.4), S_{5}(0.6)\right\}$ \\
\hline
\end{tabular}

TABLE 27: The normalized probabilistic linguistic decision matrix of the group.

\begin{tabular}{lcccc}
\hline Attributes & $x_{1}$ & $x_{2}$ & $x_{3}$ & $x_{4}$ \\
\hline$A_{1}$ & $\left\{S_{4}(0.6), S_{3}(0.4), S_{3}(0)\right\}$ & $\left\{S_{4}(0.6), S_{2}(0.2), S_{2}(0)\right\}$ & $\left\{S_{5}(0.4), S_{4}(0.4), S_{2}(0.2)\right\}$ & $\left\{S_{5}(0.4), S_{4}(0.4), S_{3}(0.2)\right\}$ \\
$A_{2}$ & $\left\{S_{3}(0.6), S_{5}(0.2), S_{2}(0.2)\right\}$ & $\left\{S_{3}(0.4), S_{2}(0.4), S_{1}(0.2)\right\}$ & $\left\{S_{4}(0.4), S_{5}(0.2), S_{1}(0.2)\right\}$ & $\left\{S_{3}(0.4), S_{2}(0.4), S_{2}(0)\right\}$ \\
$A_{3}$ & $\left\{S_{4}(0.4), S_{3}(0.4), S_{5}(0.2)\right\}$ & $\left\{S_{3}(0.6), S_{2}(0.2), S_{2}(0)\right\}$ & $\left\{S_{4}(0.4), S_{5}(0.2), S_{1}(0.2)\right\}$ & $\left\{S_{5}(0.6), S_{4}(0.4), S_{4}(0)\right\}$ \\
\hline
\end{tabular}

TABLE 28: The positive ideal solution and the negative ideal solution.

\begin{tabular}{lcccc}
\hline Attributes & $x_{1}$ & $x_{2}$ & $x_{3}$ & $x_{4}$ \\
\hline PLPIS & $(2.4,1.2,1)$ & $(2.4,0.8,0.2)$ & $(2,1.6,0.4)$ & $(3,1.6,0.6)$ \\
\hline Attributes & $x_{1}$ & $x_{2}$ & $x_{3}$ & $x_{4}$ \\
\hline PLNIS & $(1.6,1,0)$ & $(1.2,0.4,0)$ & $(1.6,1,0.2)$ & $(1.2,0.8,0)$ \\
\hline
\end{tabular}




$$
\begin{aligned}
d\left(A_{1}, L^{+}\right) & =0.4257, \\
d\left(A_{2}, L^{+}\right) & =0.8076, \\
d\left(A_{3}, L^{+}\right) & =0.4055, \\
d\left(A_{1}, L^{-}\right) & =0.6244, \\
d\left(A_{2}, L^{-}\right) & =0.1223, \\
d\left(A_{3}, L^{-}\right) & =0.6692, \\
d_{\min }\left(A_{i}, L^{+}\right) & =0.4055, \\
d_{\max }\left(A_{i}, L^{-}\right) & =0.6692 .
\end{aligned}
$$

Step 5: calculate the closeness coefficient $\mathrm{CI}\left(A_{i}\right)(i=1,2,3)$ :

$$
\begin{aligned}
& \mathrm{CI}\left(A_{1}\right)=-0.1168, \\
& \mathrm{CI}\left(A_{2}\right)=-1.8089, \\
& \mathrm{CI}\left(A_{3}\right)=0 .
\end{aligned}
$$

Step 6: rank the alternatives $A_{i}$ according to $\mathrm{CI}\left(A_{i}\right)(i=1,2,3)$ :

$$
A_{3}>A_{1}>A_{2}
$$

By comparing the proposed classical algorithm above, we can find it is only a special example of the proposed algorithms; in this paper, when $\lambda=2$, that is, the proposed algorithms extended the classical algorithm.

\section{Conclusions}

This paper presents generalized distance measures between two PLTSs with multigranular probabilistic linguistic information and the method of filling with the missing evaluation information, which can be used to deal with MAGDM problems. The main advantages of this paper can be given as follows: (1) the generalized distance measures improve the accuracy of multigranular linguistic information in the MAGDM issues, and even some evaluation information is null, a more reasonable method is presented to address the missing value of the evaluation information; (2) the parameter $\lambda$ of the generalized distance measures is a variable that can be used to obtain different distance measures formula according to the DMs' needs; since then, the rankings of the alternatives are stable; (3) under these distance measures, the presented three algorithms MGPLTOPSIS, MGPL-ETOPSIS, and MGPL-VIKOR are more available; (4) the proposed calculation method of PLTSs is more effective; (5) the entropy weight method can save more information and become more objective and accurate.

The generalized distance measures presented in this paper also have some limitations: (1) whether more appropriate ways exist to measure the distances between two PLTSs with multigranular linguistic information is a worthwhile question; (2) how to select the $\lambda$ proper to measure the distance between two PLTSs and the algorithm according to the practical problem have potential to be studied further. Some directions for further research are identified. First, the applications of these extended distance measures are interesting to study in cluster analysis and other MAGDM problems. Second, linguistic information can be expressed by interval fuzzy numbers.

\section{Data Availability}

All relevant data are available within the paper. All relevant data are available from the "Auto Home" website (http:// www.autohome.com.cn).

\section{Disclosure}

This research does not involve any human or animal participation.

\section{Conflicts of Interest}

The authors declare that there are no conflicts of interest regarding the publication of this paper.

\section{Acknowledgments}

This work was supported by the Key Projects of the Natural Science Fund of Anhui Colleges and Universities (Grant no. KJ2019A0785), the Projects of the Natural Science Fund of Anhui Colleges and Universities (Grant no. KJ2019JD17), and the Key Projects of the Humanities and Social Science Fund of Anhui Colleges and Universities (Grant nos. SK2019A0664 and SK2019A0652).

\section{References}

[1] L. A. Zadeh, "Fuzzy sets," Information Control, vol. 8, no. 3, pp. 338-353, 1965.

[2] L. A. Zadeh, "The concept of a linguistic variable and its application to approximate reasoning-I," Information Sciences, vol. 8, no. 3, pp. 199-249, 1975.

[3] V. Torra, "Hesitant fuzzy sets," International Journal of Intelligent Systems, vol. 25, no. 6, pp. 529-539, 2010.

[4] R. M. Rodriguez, L. Martinez, and F. Herrera, "Hesitant fuzzy linguistic term sets for decision making," IEEE Transactions on Fuzzy Systems, vol. 20, no. 1, pp. 109-119, 2012.

[5] J.-B. Yang, "Rule and utility based evidential reasoning approach for multiattribute decision analysis under uncertainties," European Journal of Operational Research, vol. 131, no. 1, pp. 31-61, 2001.

[6] Z. Wu and J. Xu, "Possibility distribution-based approach for MAGDM with hesitant fuzzy linguistic information," IEEE Transactions on Cybernetics, vol. 46, no. 3, pp. 694-705, 2016.

[7] H. Liu and R. M. Rodríguez, "A fuzzy envelope for hesitant fuzzy linguistic term set and its application to multicriteria decision making," Information Sciences, vol. 258, no. 3, pp. 220-238, 2014.

[8] B. Zhu, Research and application of decision making method based on preference relation, $\mathrm{PhD}$ thesis, Southeast University, Dhaka, Bangladesh, 2014.

[9] B. Zhu and Z. Xu, "Probability-hesitant fuzzy sets and the representation of preference relations," Technological and Economic Development of Economy, vol. 24, no. 3, pp. 10291040, 2018. 
[10] Q. Pang, H. Wang, and $\mathrm{Z}$. Xu, "Probabilistic linguistic term sets in multi-attribute group decision making," Information Sciences, vol. 369, no. 10, pp. 128-143, 2016.

[11] Y. Zhai, Z. Xu, and H. Liao, "Measures of probabilistic interval-valued intuitionistic hesitant fuzzy sets and the application in reducing excessive medical examinations," IEEE Transactions on Fuzzy Systems, vol. 26, no. 3, pp. 1651-1670, 2018.

[12] X. Wu, H. Liao, Z. Xu, A. Hafezalkotob, and F. Herrera, "Probabilistic linguistic MULTIMOORA: a multicriteria decision making method based on the probabilistic linguistic expectation function and the improved Borda rule," IEEE Transactions on Fuzzy Systems, vol. 26, no. 6, pp. 3688-3702, 2018.

[13] X. Gou and Z. Xu, "Novel basic operational laws for linguistic terms, hesitant fuzzy linguistic term sets and probabilistic linguistic term sets," Information Sciences, vol. 372, no. 1, pp. 407-427, 2016.

[14] P. Liu and Y. Li, "The PROMTHEE II method based on probabilistic linguistic information and their application to decision making," Informatica, vol. 29, no. 2, pp. 303-320, 2018.

[15] H. C. Liao, L. S. Jiang, Z. S. Xu, J. P. Xu, and F. Herrera, “A linear programming method for multiple criteria decision making with probabilistic linguistic information," Information Sciences, pp. 415-416, 2017.

[16] J. Li and J.-q. Wang, "An extended QUALIFLEX method under probability hesitant fuzzy environment for selecting green suppliers," International Journal of Fuzzy Systems, vol. 19, no. 6, pp. 1866-1879, 2017.

[17] X. Wu and H. Liao, "An approach to quality function deployment based on probabilistic linguistic term sets and ORESTE method for multi-expert multi-criteria decision making," Information Fusion, vol. 43, pp. 13-26, 2018.

[18] H. Liao, L. Jiang, B. Lev, and H. Fujita, "Novel operations of PLTSs based on the disparity degrees of linguistic terms and their use in designing the probabilistic linguistic ELECTRE III method," Applied Soft Computing, vol. 80, pp. 450-464, 2019.

[19] S. G. Abdolhamid, M. Mehrdad, and D. Mehdi, "Extension of the VIKOR method for group decision making with extended hesitant fuzzy linguistic information," Neural Computing and Applications, vol. 30, pp. 3589-3602, 2018.

[20] X. Zhang and X. Xing, "Probabilistic linguistic VIKOR method to evaluate green supply chain initiatives," Sustainability, vol. 9, no. 7, p. 1231, 2017.

[21] Y. X. Zhang, Z. S. Xu, and H. C. Liao, "A decision framework for water-human harmony evaluation based on entropy, cross entropy, and VIKOR methods with probabilistic linguistic term sets," Technical report, International Journal of Fuzzy Systems, 2019.

[22] X. J. Gou, Z. S. Xu, H. C. Liao, and H. Francisco, "Probabilistic double hierarchy linguistic term set and its use in designing an improved VIKOR method: the application in smart healthcare," Journal of the Operational Research Society, pp. 1-20, 2020.

[23] Z. Hao, Z. Xu, H. Zhao, and Z. Su, "Probabilistic dual hesitant fuzzy set and its application in risk evaluation," KnowledgeBased Systems, vol. 127, pp. 16-28, 2017.

[24] J. Gao, Z. Xu, and H. Liao, "A dynamic reference point method for emergency response under hesitant probabilistic fuzzy environment," International Journal of Fuzzy Systems, vol. 19, no. 5, pp. 1261-1278, 2017.
[25] I. M. Sharaf, "TOPSIS with similarity measure for MADM applied to network selection," Computational and Applied Mathematics, vol. 37, no. 4, pp. 4104-4121, 2018.

[26] M. S. A. Khan, F. Khan, J. Lemley, S. Abdullah, and F. Hussain, "Extended topsis method based on Pythagorean cubic fuzzy multi-criteria decision making with incomplete weight information," Journal of Intelligent \& Fuzzy Systems, vol. 38 , no. 8, pp. 1-12, 2019.

[27] A. Ali and T. Rashid, "Generalized interval-valued trapezoidal fuzzy best-worst multiple criteria decision-making method with applications," Journal of Intelligent \& Fuzzy Systems, vol. 38, no. 2, pp. 1-15, 2019.

[28] R. Verma, "On aggregation operators for linguistic trapezoidal fuzzy intuitionistic fuzzy sets and their application to multiple attribute group decision making," Journal of Intelligent \& Fuzzy Systems, vol. 38, no. 3, pp. 2907-2950, 2020.

[29] R. M. Rodríguez, L. Martínez, and F. Herrera, “A group decision making model dealing with comparative linguistic expressions based on hesitant fuzzy linguistic term sets," Information Sciences, vol. 241, pp. 28-42, 2013.

[30] J.-X. Wang, "A MAGDM algorithm with multi-granular probabilistic linguistic information," Symmetry, vol. 11, no. 2, pp. 127-147, 2019.

[31] B. Zhu and Z. Xu, "Consistency measures for hesitant fuzzy linguistic preference relations," IEEE Transactions on Fuzzy Systems, vol. 22, no. 1, pp. 35-45, 2014. 